\title{
Pilot Evaluation of Electricity-Reliability and Power-Quality Monitoring in California's Silicon Valley with the I-Grid ${ }^{\circledR}$ System
}

\author{
Prepared for \\ Imre Gyuk \\ Energy Storage Program \\ Office of Electric Transmission and Distribution \\ U.S. Department of Energy \\ by \\ Joseph Eto \\ Energy Analysis Department \\ Ernest Orlando Lawrence Berkeley National Laboratory \\ University of California \\ Berkeley, California 94720 \\ and \\ Deepak Divan and William Brumsickle, SoftSwitching Technologies
}

February 2004

The work described in this report was funded by the Energy Storage Program, Office of Electric Transmission and Distribution of the U.S. Department of Energy under Contract No. DE-AC0376 SF00098. 



\begin{abstract}
Power-quality events are of increasing concern for the economy because today's equipment, particularly computers and automated manufacturing devices, is susceptible to these imperceptible voltage changes. A small variation in voltage can cause this equipment to shut down for long periods, resulting in significant business losses. Tiny variations in power quality are difficult to detect except with expensive monitoring equipment used by trained technicians, so many electricity customers are unaware of the role of power-quality events in equipment malfunctioning.
\end{abstract}

This report describes the findings from a pilot study coordinated through the Silicon Valley Manufacturers Group in California to explore the capabilities of I-Grid ${ }^{\circledR}$, a new power-quality monitoring system. This system is designed to improve the accessibility of power-quality information and to increase understanding of the growing importance of electricity reliability and power quality to the economy.

The study used data collected by I-Grid sensors at seven Silicon Valley firms to investigate the impacts of power quality on individual study participants as well as to explore the capabilities of the I-Grid system to detect events on the larger electricity grid by means of correlation of data from the sensors at the different sites. In addition, study participants were interviewed about the value they place on power quality, and their efforts to address electricity-reliability and powerquality problems. Issues were identified that should be taken into consideration in developing a larger, potentially nationwide, network of power-quality sensors. 



\section{Acknowledgments}

The authors thank Imre Gyuk, DOE Energy Storage Program, Office of Electric Transmission and Distribution, and Tina Kaarsberg ${ }^{1}$ for their support of this project. We also thank the industry participants that agreed to participate in this pilot study; however, by agreement, we do not identify these firms individually. We also acknowledge the assistance of Justin Bradley of the Silicon Valley Manufacturer's Group, and Joe Desmond of the SVMG Energy Committee for their contributions to the project. The report benefited greatly from reviews of the draft report provided by Alex McEachern, Ashok Sundaram, John DeSteese, Bruce Lonie, Roseanna Lerma, Tom Schneider, and Lumi Valencia. All errors and omissions remain the responsibility of the authors.

\footnotetext{
${ }^{1}$ Ms. Kaarsberg is currently on the staff of the Energy Subcommittee of the Committee on Science, U.S. House of Representatives.
} 
Pilot Evaluation of Electricity-Reliability \& PQ Monitoring in CA's Silicon Valley with the I-Grid System 


\section{Table of Contents}

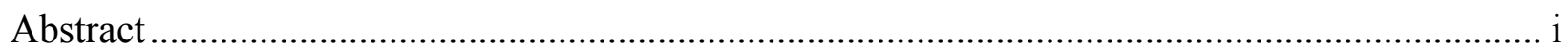

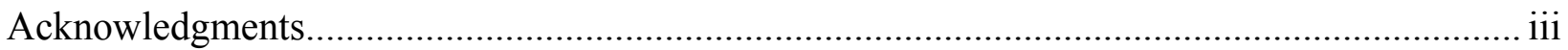

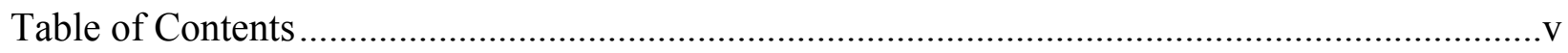

List of Figures and Tables...................................................................................................... vii

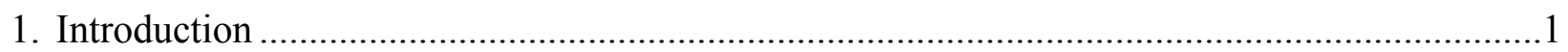

2. The Growing Importance of Power Quality for Electricity Reliability, Viewed from the

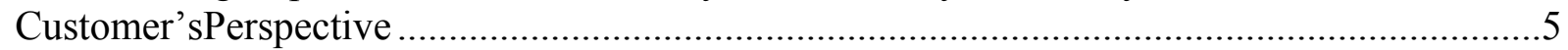

3. Description of the I-Grid Power-Quality and Reliability Monitoring System.............................7

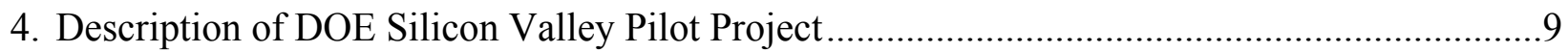

5. Review and Assessment of Power-Quality and Electricity-Reliability Events Recorded During

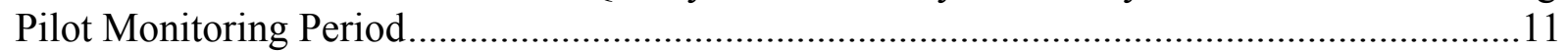

5.1 Review of Significant Events Recorded During Monitoring Period ..................................15

5.1.1 July 1, 2002 Car-Pole Accident near Firm 1...........................................................17

5.1.2 October 19, 2002 Short Voltage Sag Event at Firm 1 ….........................................17

5.1.3 November 7, 2002 Region-wide Wind Storms................................................18

5.1.4 December 27, 2002 Firm 3 Campus Distribution Transformer Failure......................20

5.1.5 January 23, 2003, Airplane Hit 500-kV Transmission Line .....................................20

5.1.6 February 2, 2003 Transmission Level Event, Possibly Caused by Earthquake.........21

5.2 Summary of Findings from Pilot Data Collection ...........................................................23

6. Customer Views on Electricity Reliability and Power Quality..................................................25

6.1 The Economic Cost of Electricity-Reliability and Power-Quality Problems ....................25

6.2 Perceptions of Power Quality and Electricity Reliability, Including Utility Relations .....27

6.3 Steps Taken to Address Electricity Reliability and Power Quality, Including Payback on

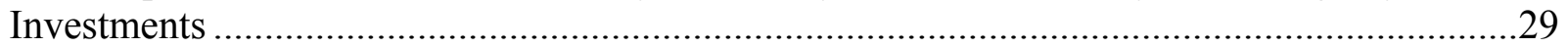

6.4 Barriers to Iimplementing Electricity-Reliability and Power-Quality Solutions................30

7. Toward Development of a Living National Database of Electricity Reliability and Power Quality 33

7.1 Recruiting Participants and Installing Monitors ………....................................................33

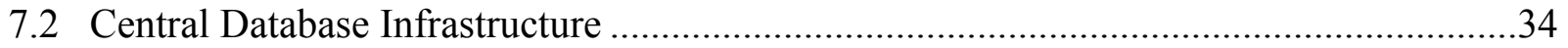

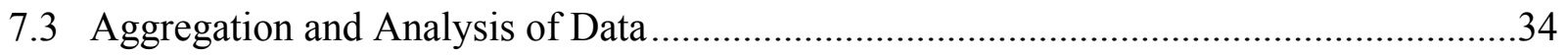

Appendix. I-Sense Monitor Summary Specifications ……………................................................

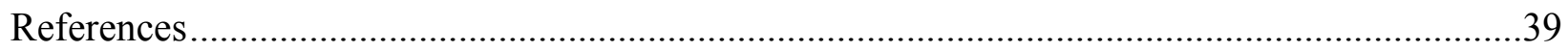


Pilot Evaluation of Electricity-Reliability \& PQ Monitoring in CA's Silicon Valley with the I-Grid System 


\section{List of Figures and Tables}

Figure 1. Representative Power-Quality Data and the CBEMA 1996 Tolerance Curve................. 6

Figure 2. Locations of Participating Firms. ............................................................................ 10

Figure 3. Magnitude-Duration Summary of all Significant Power Quality and Electricity

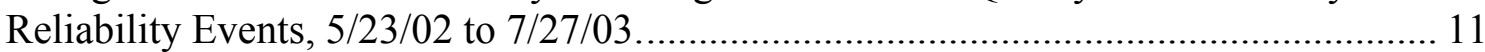

Figure 4. Summary of Single-Phase Monitors Data with ITI curve overlaid............................... 12

Figure 5. Summary of Three-Phase Monitors Data with ITI curve overlaid................................ 12

Figure 6. Summary of Voltage Sag and Power InterruptionEvents, 5/23/02 to 7/27/03 ............. 13

Figure 7. Number of Eents Falling Below the ITI Curve ........................................................... 14

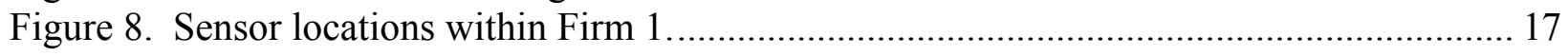

Figure 9. 10/19/02 Event Voltage Waveforms …………......................................................... 18

Figure 10. Summary of Voltage Sag Event Reported by 16 monitors, Nov. 7, 2002, 11:41:28

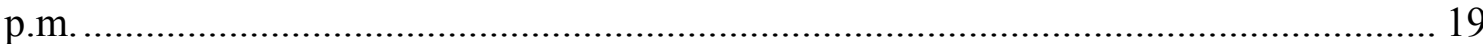

Figure 11. 11/7/02 Typical Event RMSVoltage Profiles at Four Sites........................................ 20

Figure 12. 2/2/03 Event Voltage Waveform and RMS Voltage Profile....................................... 22

Figure 13. 2/2/03 event voltage waveform, and RMS Voltage Profile. ..................................... 23

Table 1. Occurrences of significant Electric-Reliability and Power-Quality Events at Firm 1. .16 Table 2. The Economic Costs of Electricity Reliability and Power Quality ............................... 26

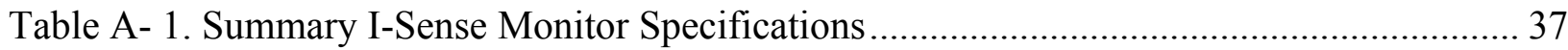

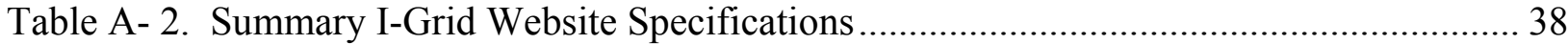





\section{Introduction}

The U.S. electricity system has been described as one of the most reliable in the world and, at the same time, as an antiquated system in dire need of new investment. Little solid information is available to support either claim. Utilities' data on the reliability of electricity service is not collected consistently and is not readily available. Moreover, information on power quality, a key aspect of electricity reliability from the customer's point of view, is rarely collected at all (Warren, Pearson, Sheehan 2002).

Power quality is a growing concern because today's electricity-consuming equipment - ranging from personal computers in offices to automated manufacturing processes - is much more susceptible to power-quality problems than older equipment, such as conventional lighting and motors. Power-quality problems - typically sags, swells, or interruptions in voltage - arise from both routine grid operations and natural events (e.g., lightning strikes). Although these problems are typically last only fractions of a second, they can cause hours of manufacturing downtime. Traditional utility measures of electricity grid reliability, which focus on the duration of grid events, do not capture power-quality events and their profound impact on customers.

The absence of consistent and geographically comprehensive information about the prevalence and impact of power-quality problems on the nation's economy presents challenges for consumers and policy makers/regulators. From the consumer's perspective, awareness and diagnosis of power-quality events are key concerns. Because of the short duration of powerquality events, customers are rarely aware that a power-quality event has taken place. Although power-quality problems are one reason that manufacturing processes may stop or operate poorly, there are other possible reasons, including mechanical failures, impurities in feedstock, and poorly calibrated operations.

Even if a customer is aware that a power-quality event could be the cause of manufacturing problems, the expertise and technology required to diagnose and confirm power-quality problems are expensive. Power-quality monitoring devices typically cost $\$ 5,000-10,000+$ and must be used by technicians with specialized training.

Data on power quality is almost completely lacking and, although data on the larger issue of electricity reliability are collected by utilities, these data are not consistently defined and categorized from utility to another. Therefore, even though our specific focus in this report is on power-quality issues, we frequently refer to the larger category of electricity reliability as well because reliability and power quality issues are closely related and consistent information is lacking on both. Section 2 of this report gives a brief technical overview of the growing linkage between electricity reliability and power quality as viewed from the customer's perspective.

From the public policy perspective, reliable information on both electricity reliability and power quality is a public good that is not provided for adequately by the market. The last systematic information published on power quality was developed by the Electric Power Research Institute (EPRI) seven years ago and included only 300 monitored sites at 24 utilities in selected regions of the country (Electrotek 1996). These data are now outdated and can only be obtained under license from EPRI. Limited results intended to be statistically representative of the country as a 
whole have been presented publicly (Sabin 1998). Results of a follow-on EPRI survey were published in 2003 by EPRI, but have not been presented in a public forum.

Without current data on power quality, it is difficult to determine how to remedy power-quality problems. The electricity grid was never designed to provide perfect reliability or power quality, and it would be prohibitively expensive to construct such grid. It may be more cost effective and fair for society as a whole to allow individual customers to reduce the susceptibility of their equipment to power-quality (and other reliability) events rather than to require all ratepayers to pay for grid improvements that benefit only some ratepayers. However, without consistent information on electricity reliability and power quality, it is difficult for both customers and policy makers to assess these tradeoffs.

This report describes the findings from a pilot study, coordinated through the Silicon Valley Manufacturers Group (SVMG), ${ }^{2}$ to explore the capabilities of a new power-quality monitoring system, the I-Grid ${ }^{\circledR}$. This system is designed to improve the accessibility of power-quality information and to increase understanding of the growing importance to the economy of electricity reliability and power quality. The I-Grid consists of low-cost monitoring devices and a web database and analysis capability that is easy to use without specialized training. When an I-Grid monitoring device detects a voltage sag or interruption, it time-stamps and precisely records the data; after voltage returns to normal, the device automatically dials up and uploads information on the event to a web server. Monitor owners and others can then view and analyze the event on a secure website. Section 3 presents an overview of the I-Grid.

Our pilot study involved installing 22 monitors at seven customer sites throughout the southern portion of the San Francisco bay area (known as "Silicon Valley" because of the large number of high-technology firms there). Data were collected from June 2002 through July 2003. Section 4 describes the recruitment process for participants in the pilot study and the firms that agreed to participate.

Data from I-Grid's individual monitors allows us to identify power-quality events and determine their impact on individual customers. In addition, because the data from all monitors are uploaded to a central repository, we can correlate data from multiple monitors to determine whether events recorded at one site were detected or had impact elsewhere. From this information, we can assess likely impacts of power-quality events on adjacent customers who do not have monitors and draw conclusions about the state of the electricity grid. Section 5 reviews the reliability and power-quality incidents recorded during the study period.

The changing structure of the U.S. economy, coupled with the proliferation of electronic equipment in all sectors, has increased the economy's vulnerability to electricity-reliability and power-quality problems. Estimates of the annual costs of this vulnerability range consistently in the $\$ 10$ s of billions, and some exceed $\$ 100$ billion (Eto et al. 2001). However, little information is available about what these costs consist of and, more importantly, about what customers are doing to address the problem.

\footnotetext{
2 The Silicon Valley Manufacturing Group (SVMG) involves principal officers and senior managers of member companies in a cooperative effort with local, regional, state, and federal government officials to address major public-policy issues affecting the economic health and quality of life in Silicon Valley. See http://www.svmg.org/
} 
This pilot project uses a case-study approach based on interviews with participants to understand the value they place on reliability and to identify emerging trends and issues in their efforts to address electricity-reliability and power-quality problems. Section 6 summarizes the results of these interviews; the results are organized around four thematic issues:

- The economic cost of electricity-reliability and power-quality problems.

- Perceptions regarding electricity reliability and power quality, including utility relations.

- Steps taken to address electricity-reliability and power-quality issues, including paybacks of investments.

- Barriers to implementing solutions to power-quality problems.

This pilot effort is also a proof-of-concept study to identify the issues that might arise in creating a much larger network of low-cost power-quality monitoring devices. Section 7 discusses these issues. 



\section{The Growing Importance of Power Quality for Electricity Reliability, Viewed from the Customer's Perspective ${ }^{3}$}

Assessment of electricity reliability and power quality involves looking at electromagnetic deviations from the ideal service that the U.S. electricity distribution system is designed to provide: a pure 60-cycle-per-second alternating current at a designated voltage (120 volts for residential customers or 480 volts for many commercial or industrial customers). Any deviation from this standard that causes customers' equipment to fail or malfunction is considered a reliability "event." Sustained interruptions (blackouts), which occur when voltage falls to zero for more than one minute (typically, five minutes or more), are the reliability problem with which most electricity consumers have the greatest direct experience and are the key phenomena captured in traditional utility reliability statistics.

However, for many customers, the subset of reliability problems known as power-quality events - subtle deviations in voltage, sometimes observed as a "flicker" in lighting or other electrical devices and sometimes imperceptible - pose a far more significant problem than outages because of their much greater frequency of occurrence. The most common small deviation is a voltage "sag" - a drop in (but not complete loss of) voltage for a short period of time (i.e., from a few cycles to a few seconds). ${ }^{4}$ Voltage sags can be caused by natural events (e.g., trees falling on power lines or lightning striking lines or transformers), utility activities (e.g., routine switching operations or human error), or customer activities (e.g., starting of large motors).

Although in the past most electricity-consuming devices could "ride through" voltage sags (e.g., lights might dim momentarily), many of the electricity-consuming devices associated with today's digital economy (e.g., equipment controlled by programmable logic chips) cannot tolerate a partial drop in voltage for even a fraction of a second. Voltage sags may cause this equipment to shut down and remain off even after service is restored to normal levels. Voltage sags are rapid and not easily detectable by an untrained observer, so consumers may not realize that a power-quality "event" caused their equipment to fail or stop operating. Power-quality events are not included in reliability statistics reported by utilities (e.g., SAIFI, SAIDI, CAIDI, CAIFI, MAIFI).

Figure 1 illustrates the relationship between voltage sags and equipment performance. The figure plots individual, recorded power-quality events by their duration and magnitude. Superimposed on the figure is the Computer Business and Equipment Manufacturers Association (CBEMA) 1996 tolerance curve, which is a guideline for voltage tolerance of typical electronic equipment. Typical equipment should be able to tolerate voltage sags of durations and magnitudes above the curve without interruption in function. As indicated by these data, a significant number of recorded events fall below the curve; these events would cause failure or operational problems for susceptible equipment.

\footnotetext{
${ }^{3}$ The material presented in this section is adapted from Divan, Brumsickle, and Eto 2003.

${ }^{4}$ EPRI's landmark study of power quality found that voltage-related power-quality events accounted for 90 percent of all power-quality events (Electrotek 1996).
} 


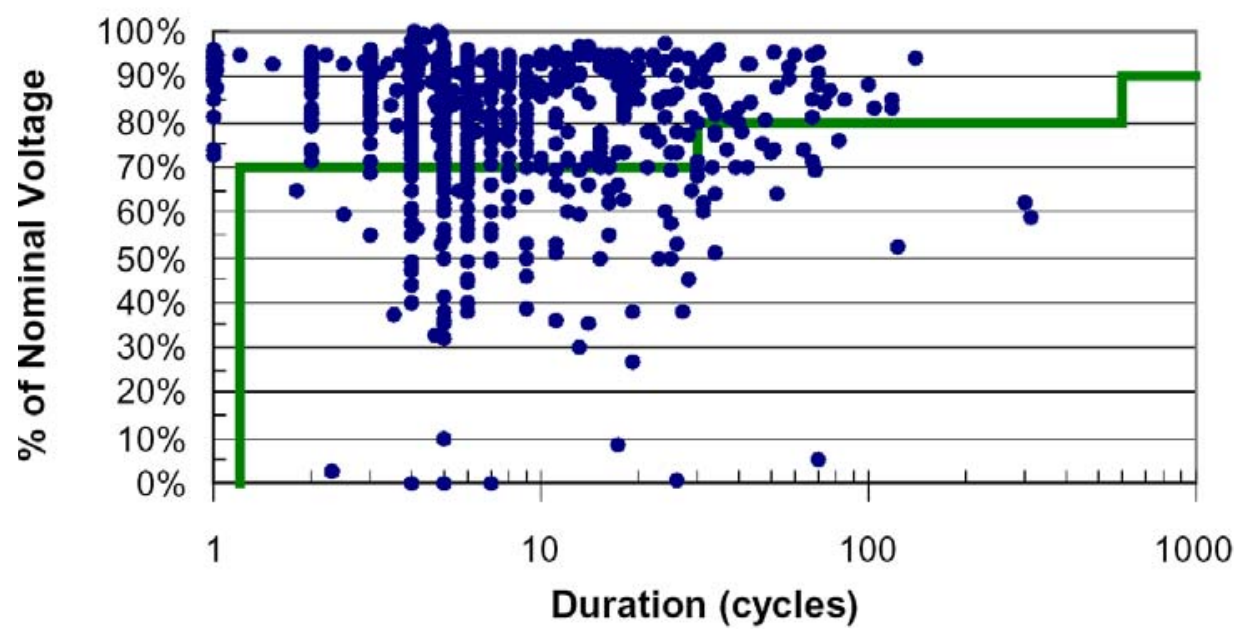

Figure 1. Representative Power-Quality Data and the CBEMA 1996 Tolerance Curve (Source: Sematech 1999).

Increased reliance on devices that are susceptible to power-quality problems means that the U.S. economy's vulnerability to electricity-supply interruptions in general, and to momentary supply deviations in particular, has increased. Thus, the lack of relationship noted in the introductionbetween the statistics that utilities collect about electricity reliability and the power-quality events that have profound impact on consumers - has great economic significance. Without these data, we cannot determine whether it is most cost effective to harden customer's equipment to be more tolerant of power-quality events or to makes changes to the grid and its operation to prevent damage and loss from power-quality events. 


\section{Description of the I-Grid Power-Quality and Reliability Monitoring System}

The I-Grid system, developed by SoftSwitching Technologies, ${ }^{5}$ is a web-based, power-quality and reliability monitoring and alarm system (Divan et al. 2002). The system relies on widespread deployment of a large number of low-cost "I-Sense"TM power monitors throughout a geographic region of the grid. The monitors continuously capture 10-minute $\mathrm{min} / \mathrm{max}$ and average root mean squared (RMS) voltages as well as detailed data on grid voltage deviation events including outages, blackouts, brownouts, interruptions, and short-duration power-quality disturbances such as voltage sags and swells, which, as noted in the previous section, can pose significant reliability concerns from the customer's point of view. ${ }^{6}$

The sensors transmit data via the internet to a central database and website. Information on grid events is displayed at the website, and near-real-time notification of events is sent to designated individuals or groups. With these functions, the website acts like a live "web cam" for areas of the electricity grid. In addition, web-based forms record customer observations about the cause of the event, if known and the effect of the event on company processes, including cost of downtime, if known.

These sensors are significantly less expensive than conventional power quality monitors ( $\$ 450$ 600 per I-Sense device compared to $\$ 5,000-10,000$ for conventional power quality monitors that require specialized technicians to use properly) and offer targeted, highly specific functionality. ${ }^{7}$ In addition to internet communications and centralized data processing and aggregation, the monitors utilize low-cost digital signal processors and electronics. Reliance on standard web browsers eliminates the need for the significant investment in software and hardware infrastructure that is typically required for other monitoring systems.

The I-Grid differs from other power-quality monitoring methodologies by using a systemcentered (rather than a monitor-centered) approach, providing access to real-time as well as historical data on site-specific power quality and reliability, and offering the ability to correlate events recorded at geographically dispersed locations. More importantly, the system's low cost per node means that broad-based deployment of monitoring across the electricity grid is more

\footnotetext{
${ }^{5}$ SoftSwitching Technologies ${ }^{\mathrm{TM}}$ is a spin-off from the University of Wisconsin that designs and manufactures power monitoring and power electronics solutions for power-quality applications. http://www.softswitching.com/ ${ }^{6}$ EPRI-Power Electronics Applications Center (PEAC) has recently completed a comprehensive test report that confirms the accuracy of the power-quality information collected by I-Sense monitors and their ability to capture voltage sags and interruptions (EPRI 2003).

${ }^{7}$ The I-Grid system in its present configuration does not monitor all possible power-quality phenomena; it monitors only voltage-related power-quality events, which, as noted above, account for 90 percent of all power-quality events. Summary specifications are listed in the Appendix.
} 
financially feasible than it has been in the past. A large number of monitors and appropriate analysis software could allow data to be clustered and aggregated over large geographic areas, to assess reliability and power quality for individual customers as well as the state of the electricity grid as a whole. The I-Grid's use of accurate, synchronized timestamps across geographically dispersed sensors is critical for wide area monitoring. 


\section{Description of DOE Silicon Valley Pilot Project}

SoftSwitching Technologies and the U.S. Department of Energy's (DOE’s) Lawrence Berkeley National Laboratory, in conjunction with the SVMG, initiated a pilot I-Grid project in 2002. The project's overall objective was to assess the effectiveness of I-Grid's web-based electricityreliability and power-quality monitoring system based on deployment of low-cost sensors within a geographic region. Specifically, we field-tested the I-Grid system's ability to detect grid-level events through a network of sensors deployed at individual customer sites. A secondary objective was to better understand the impacts of electricity reliability, primarily power quality, on customers. Findings for this second objective came from interviews with project participants.

Participants were recruited with assistance from SVMG, which provided contact information for members known to be interested in electricity-reliability and power- quality issues. We also made an invited presentation on the project to a meeting of the SVMG Energy Policy Committee.

Participants were asked to install and register a small number of I-Sense monitors at an appropriate site within their facilities. Typically, monitors were installed at service delivery points and panels serving susceptible loads. Participants were also asked to respond to notifications of power-quality events by completing an on-line form regarding downtime occurrences coincident with each event (to maintain confidentiality, all process-related information was purged of company identity). In return, participants received email notification of power-quality events after the events were recorded and access to the I-Grid website for additional diagnostic information about the events.

Seven firms/institutions ultimately agreed to participate in the pilot and installed a total of 22 ISense monitors. An eighth firm agreed to participate but was not able to coordinate installation of monitors in time to include data in the analysis. Figure 2 shows the approximate locations of the monitoring sites.

To maintain the anonymity of participants, the participant companies and institutions are numbered Firm 1 through Firm 8:

- Firm 1 is a semiconductor fabrication facility. Utility service is three-phase at 480 volts. Firm 1's characteristics are further described in the Section 5 case studies.

- Firm 2 is a high-tech research and development (R\&D) campus with offices and associated labs. Three buildings on the same campus are monitored. Utility service is three-phase at 480 volts.

- Firm 3 is a university campus including large dormitories, library, offices, and classrooms. Two buildings are monitored, containing offices, data center, and library. Utility service is at transmission-level three phase. Firm 3 provides its own distribution substation and campus distribution system, as well as local generation capability.

- Firm 4 is an electrical supply business with distribution and storefront facilities. Offices, some with light industrial shops, at five buildings in five different cities are monitored. Utility service is Single-phase. 
- Firm 5 is an electrical consulting firm, with offices and a testing lab, located in a light industrial park suite. Utility service is three-phase, 120/208 volts.

- Firm 6 is a large university and national laboratory. Three buildings on one campus and one building on another nearby campus, with offices and labs, are monitored. Utility service is three-phase; all monitors at Firm 6 are single-phase.

- Firm 7 is an industrial manufacturing plant comprising one very large building. Three-phase utility service is at transmission-level voltage. The industrial distribution system supplies plant loads. One single-phase monitor is installed at an office branch circuit outlet within the plant.

- Firm 8 is a semiconductor fabrication tool manufacturer. Firm 8 participated in interviews but was unable to install monitors in time for inclusion in data analysis.

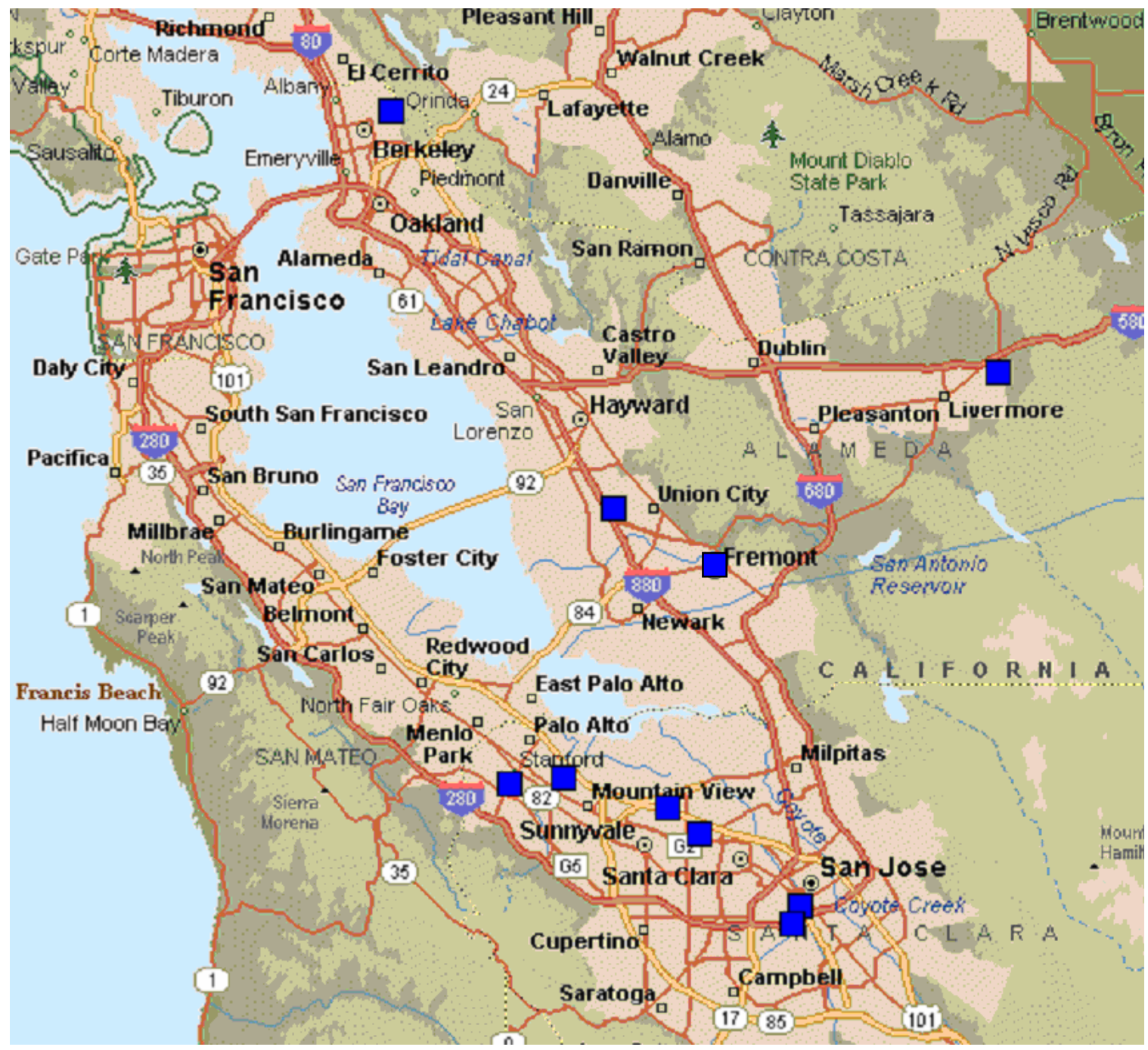

Figure 2. Locations of participating firms (large squares). 


\section{Review and Assessment of Power-Quality and Electricity-Reliability Events Recorded During Pilot Monitoring Period}

The first monitors were installed in late May 2002. Figure 3 shows an overall summary of the significant power-quality and reliability events recorded from May 2002 to late July, 2003, together with the Information Technology Industry Council (ITI, formerly CBEMA) curve for typical equipment susceptibility to voltage disturbances. ${ }^{8}$

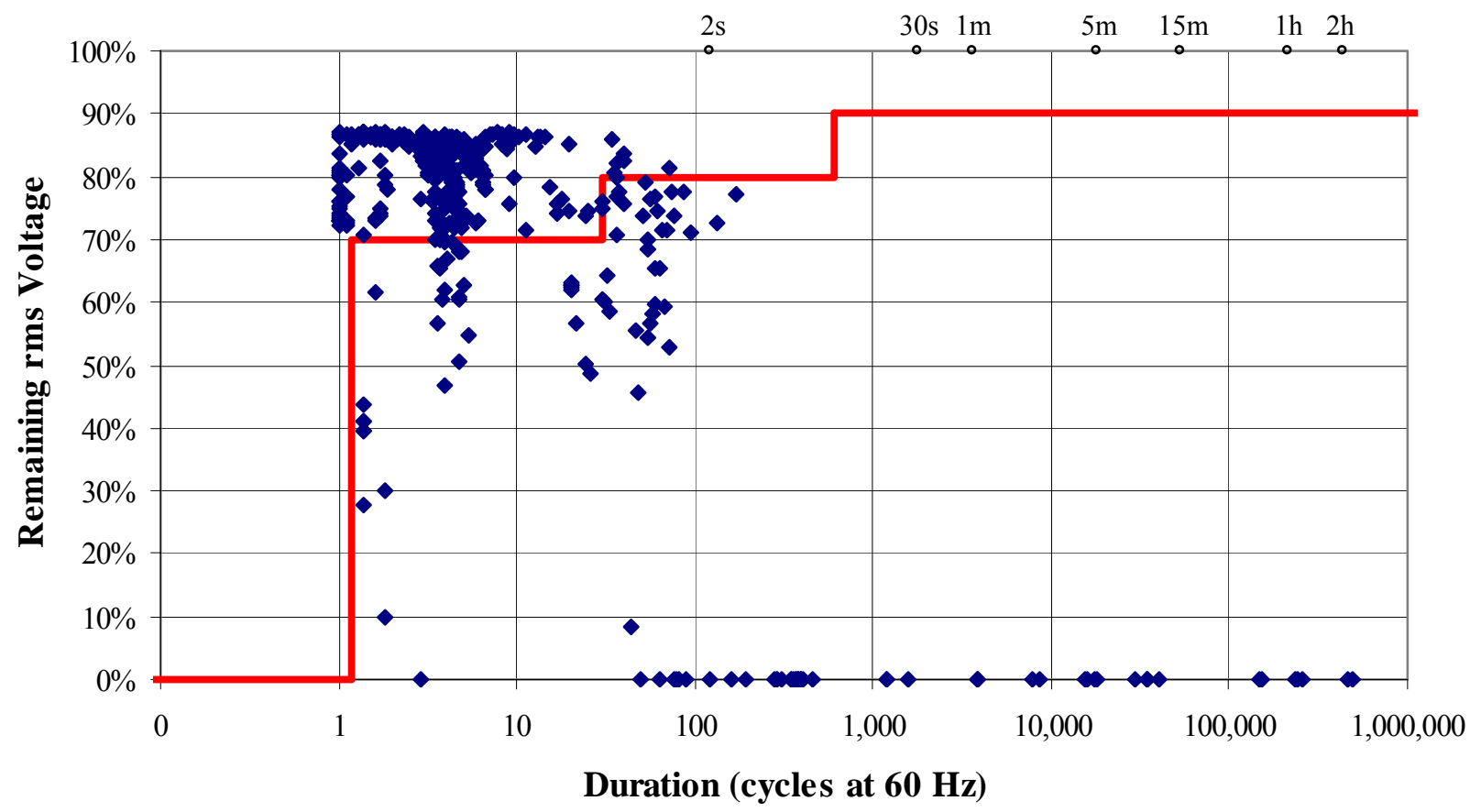

Figure 3. Magnitude-Duration summary of all significant power quality and electricity reliability events, 5/23/02 to 7/27/03, with ITI/CBEMA curve overlay.

In all, 402 significant voltage sag events (88 percent of total events) and 53 interruptions (12 percent of total events) were recorded. ${ }^{9}$ No voltage swells or longer-term brownouts were recorded during the monitoring period. Of the interruptions, 12 were longer than five minutes in duration, meeting the definition commonly used by utilities of a power "outage." Four of the participating firms are large (more than one megawatt) electricity consumers. Only one of these large utility customers experienced an outage, when a car hit a utility pole near the plant, which accounts for three of the recorded outages.

Although the sample in this data set may be too small to allow generalizations, a revealing split in the reliability and quality of electric power becomes apparent when the data are segregated by monitor type; larger commercial and industrial (C\&I) electricity

\footnotetext{
${ }^{8}$ The ITI curve is also known as the CBEMA 2000 curve (ITI 2000). Recommended interpretation is provided by ITI on its website: http://www.itic.org/technical/iticurv.pdf.

${ }^{9}$ It is believed that the recorded interruptions (i.e., the points along the $\mathrm{x}$-axis indicating 0 voltage) include a small number of cases where the monitor was purposely disconnected or a scheduled interruption of internal facility power occurred.
} 
consumers with three-phase service experience far fewer power-quality events than were experienced by smaller, light industrial or office locations with single-phase service.

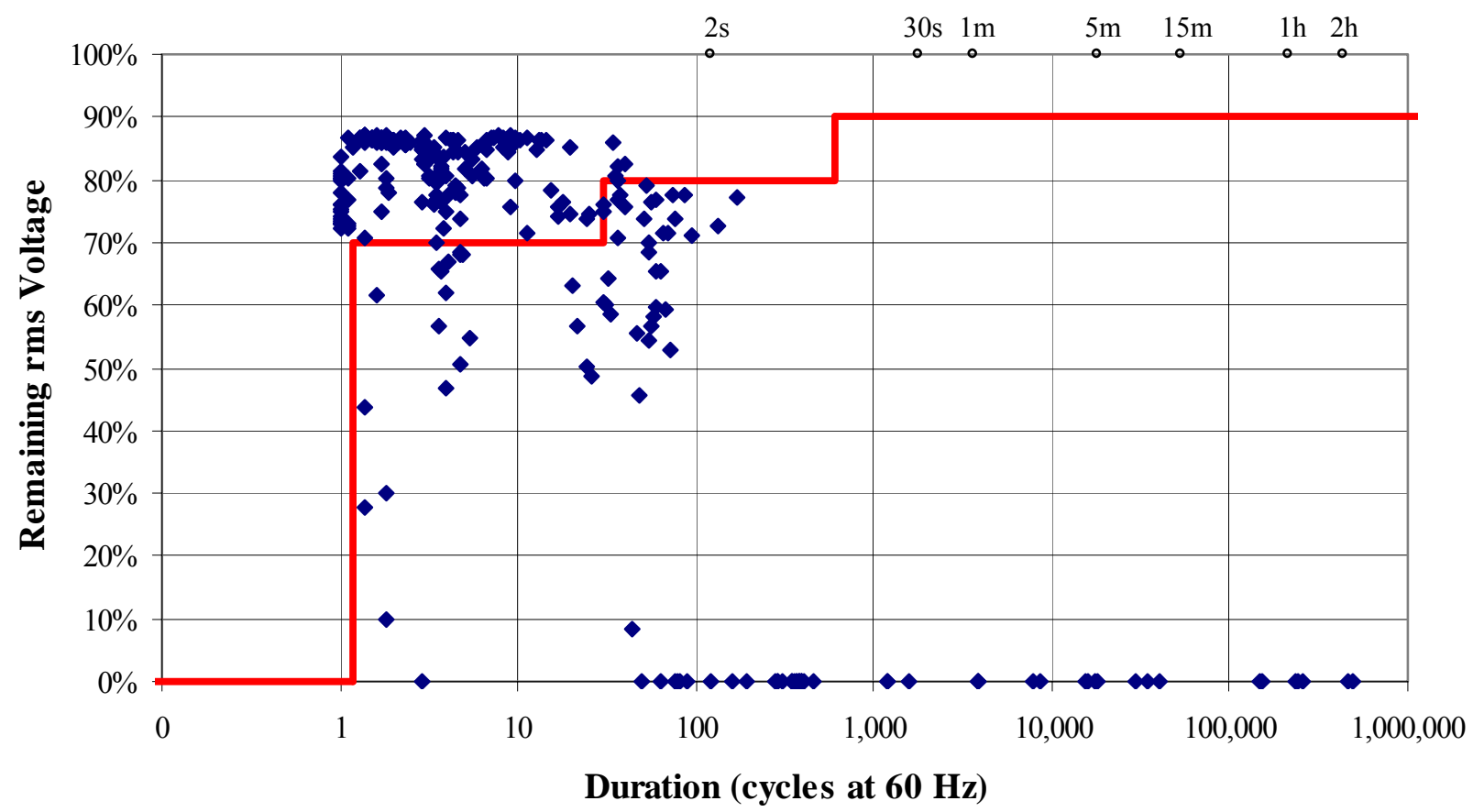

Figure 4. Summary of Single-Phase Monitors Data with ITI curve overlaid. (263 sags, 51 interruptions, 104 events below the ITI curve).

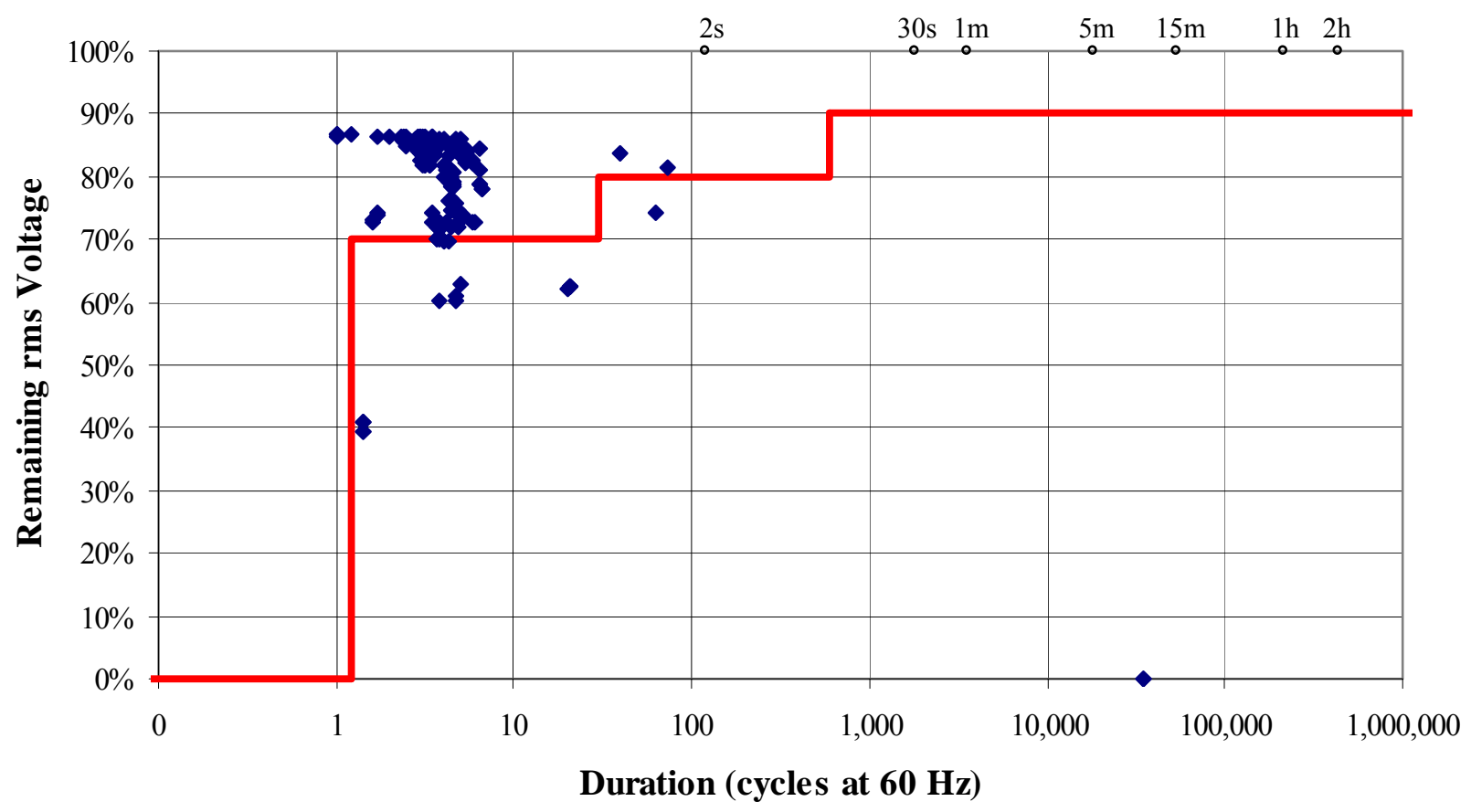

Figure 5. Summary of Three-Phase Monitors Data with ITI curve overlaid. (139 sags, 2 interruptions, 18 events below the ITI curve). 
Figures 4 and 5 are the magnitude-duration plots for all single-phase sensor events and all three-phase sensor events, respectively. These figures clearly show that the three-phase C\&I customers are much less likely to suffer power interruptions (those events along the horizontal axis) than are the single-phase customers. The larger C\&I customers experienced an average of 17.4 voltage sags per monitor during this period but only 0.3 interruptions per monitor. In contrast, the single-phase monitors recorded an average of 20.2 voltage sags per monitor and 3.9 interruptions per monitor. The experiences of the one-phase and three-phase monitor sites are summarized in the pie charts in Figure 6.
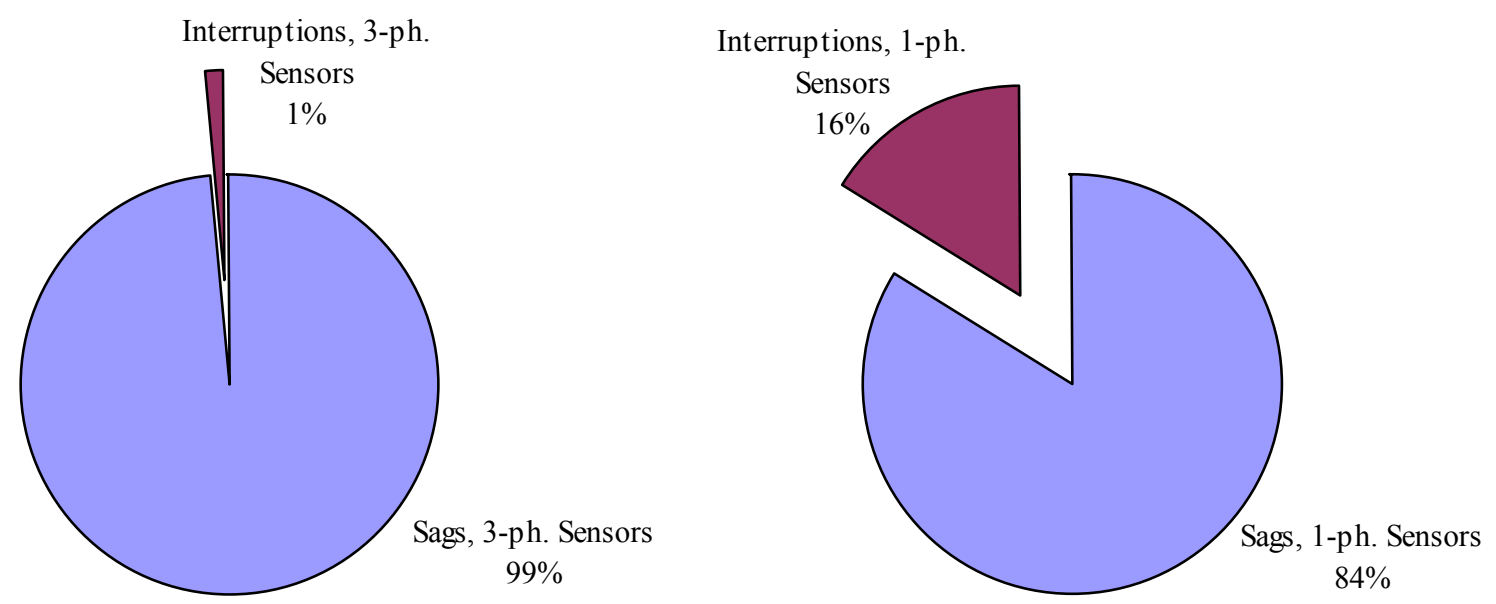

Figure 6. Summary of voltage sag and power interruption events, 5/23/02 to 7/27/03, recorded by three-phase sensors (left) and single-phase sensors (right).

The chronology of the data for events that fell below the ITI curve for equipment susceptibility is of interest. Figure 7 contrasts the aggregation of those events recorded by single-phase and three-phase monitors over time. We see that the three-phase monitors, representing larger commercial and industrial customers, experienced far fewer events where voltage fell below the ITI tolerance curve and that those events occurred on only a few discrete days. By contrast, a steady stream of below-ITI events was captured by the single-phase monitors.

It is also notable that, overall, voltage sags that do not dip below 50-percent remaining voltage predominate, and all but two of the voltage sags were less than 2.0 seconds (120 cycles) in duration. 
Number of Event
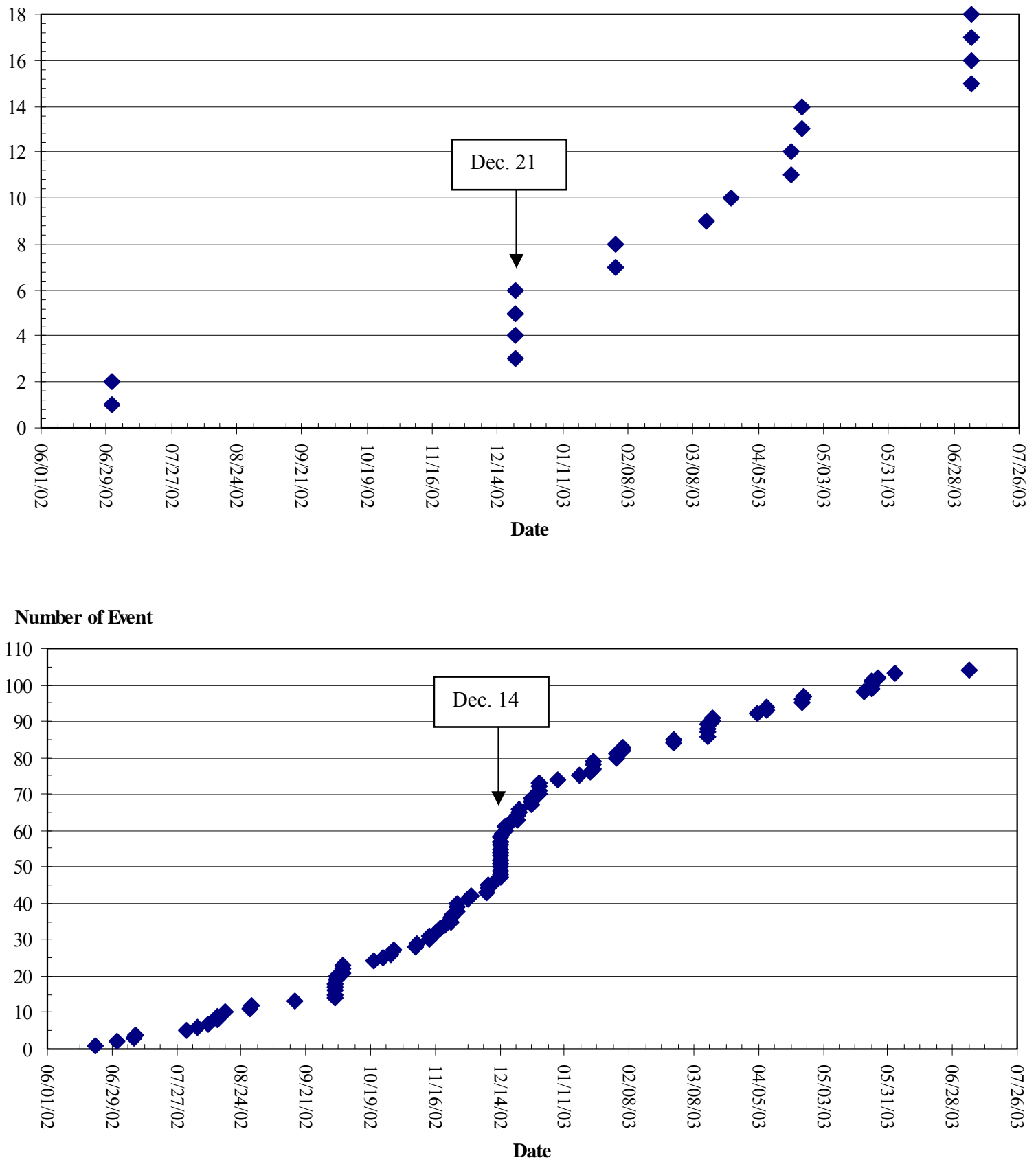

Figure 7. Number of events falling below the ITI curve, as recorded by date. Three phase monitors (top) and single phase monitors (bottom). 


\subsection{Review of Significant Events Recorded During Monitoring Period}

Firm 1 is a relatively large manufacturing plant with a nearly-ideal deployment of monitors (described further below). With one exception, the details below focus on power-quality events recorded at Firm 1; some were recorded only at Firm 1, and some were felt at other firms as well, as noted in each case. In one case, the event occurred at Firm 3.

Sixteen significant power-quality events were recorded on 15 different days by one or more sensors at Firm 1 during the period from June 26, 2002 to July 27, 2003. These events are summarized, and correlated with records from other participating firms, in Table 1on the next page.

The table shows that:

- Some events were seen only by a single sub-circuit within Firm 1.

- Some events were experienced only in one half of Firm 1 and were not seen in the other half of the building.

- Some events were seen across Firm 1, but not at other locations.

- Some events were recorded only by three-phase monitors and not seen by singlephase monitors.

- Some events were seen at Firm 1 as well as several other Firms that are served by different distribution companies. These events were propagated on the transmission system.

- The transmission system is apparently configured differently at different times: when events affected other firms in addition to Firm 1, the set of other firms was not always identical.

The case studies below highlight key information obtained from or illustrated by the power-quality data recorded for Firm 1 and, in some cases, other firms as well. All voltage waveforms and rms profiles shown below are copied directly from the I-Grid website display. 
Table 1. Occurrences of significant electric-reliability and power-quality events at Firm 1. Also shown are coincident (identical timestamp) events captured at other monitor sites, at other firms.

\begin{tabular}{|c|c|c|c|c|c|c|c|c|c|c|c|c|c|c|c|c|c|}
\hline & & & vent & tes: & & & & & & & & & & & & & \\
\hline Firm & Sensor & Site & $7 / 1 / 02$ & 9/29/02 & $10 / 19 / 02$ & $11 / 7 / 02$ & $11 / 13 / 02$ & $12 / 14 / 02$ & $12 / 21 / 02$ & $1 / 23 / 03$ & $2 / 2 / 03$ & $3 / 8 / 03$ & $4 / 19 / 03$ & $4 / 23 / 03$ & $7 / 5 / 03$ & $7 / 7 / 03$ & $7 / 23 / 03$ \\
\hline 1 & $1 \mathrm{P}$ & Block 1 & - & - & $\bullet$ & $\bullet \bullet \bullet$ & $\bullet \bullet \bullet \bullet$ & - & $\bullet$ & - & 0 & - & - & - & $\bullet$ & - & - \\
\hline 1 & $1 \mathrm{P}$ & Block 2 & $\bullet$ & - & $\bullet$ & $\bullet$ & - & $\bullet$ & $\bullet$ & - & o & $\bullet$ & - & - & $\bullet$ & - & $\bullet$ \\
\hline 1 & $3 \mathrm{P}$ & Block 1 & - & ○ & $\bullet$ & $\bullet \bullet \bullet$ & - & $\bullet$ & $\bullet$ & $\bullet$ & $\bullet \bullet$ & $\bullet$ & $\bullet$ & $\bullet \bullet$ & $\bullet$ & $\bullet$ & $\bullet$ \\
\hline 1 & $3 P$ & Block 1 & - & o & $\bullet$ & $\bullet \bullet \bullet$ & - & $\bullet$ & $\bullet$ & $\bullet$ & $\bullet \bullet$ & $\bullet$ & $\bullet \bullet$ & $\bullet \bullet$ & $\bullet$ & $\bullet$ & $\bullet$ \\
\hline 1 & $3 \mathrm{P}$ & Block 2 & $\bullet$ & $\bullet$ & $\bullet$ & $\bullet \bullet \bullet$ & - & $\bullet$ & $\bullet$ & $\bullet$ & $\bullet \bullet$ & $\bullet$ & $\bullet \bullet$ & $\bullet \bullet$ & $\bullet$ & $\bullet$ & $\bullet$ \\
\hline 1 & $3 \mathrm{P}$ & Block 2 & - & - & - & $\bullet \bullet \bullet$ & - & - & $\bullet$ & $\bullet$ & $\bullet \bullet$ & $\bullet$ & $\bullet \bullet$ & $\bullet \bullet$ & • & • & - \\
\hline 2 & $3 \mathrm{P}$ & Bldg. 1 & - & - & - & 0 & - & - & - & - & $\bullet \bullet$ & - & $\mathrm{N}$ & $\mathrm{N}$ & - & 0 & - \\
\hline 2 & $3 \mathrm{P}$ & Bldg. 2 & - & - & - & $\circ \bullet$ & - & - & - & - & $\bullet \bullet$ & - & $\bullet \bullet$ & $\bullet \bullet$ & - & o & - \\
\hline 2 & $3 \mathrm{P}$ & Bldg. 3 & - & - & - & $\bullet$ & - & - & - & - & $\bullet \bullet$ & - & $\bullet \bullet$ & $\bullet \bullet$ & - & o & - \\
\hline 3 & $1 \mathrm{P}$ & Bldg. 1 & - & - & - & 0 & - & - & - & $\bullet \bullet \bullet$ & $\bullet \bullet$ & - & - & $\bullet \bullet$ & - & $\bullet$ & - \\
\hline 3 & $1 \mathrm{P}$ & Bldg. 2 & - & - & - & $\bullet \bullet \bullet$ & - & - & - & $\bullet \bullet \circ$ & $\bullet \bullet$ & - & $\bullet$ & $\bullet \bullet$ & - & - & - \\
\hline 4 & $1 \mathrm{P}$ & Location 1 & - & - & - & $\bullet$ & - & - & - & - & - & - & - & - & - & $\mathrm{N}$ & - \\
\hline 4 & $1 \mathrm{P}$ & Location 2 & - & - & - & - & - & - & - & - & - & - & - & - & - & - & - \\
\hline 4 & $1 \mathrm{P}$ & Location 3 & - & - & - & $\bullet \bullet \bullet$ & - & - & - & • & $\bullet \bullet$ & - & - & $\bullet \bullet$ & - & • & - \\
\hline 4 & $1 \mathrm{P}$ & Location 4 & - & - & - & $\bullet$ & - & - & - & - & O० & - & - & $\bullet \bullet$ & - & - & - \\
\hline 4 & $1 \mathrm{P}$ & Location 5 & - & - & - & $\bullet$ & - & - & - & - & ০০ & - & •• & - & - & - & - \\
\hline 5 & $3 \mathrm{P}$ & - & - & - & - & $\bullet$ & - & - & - & - & $\bullet \bullet$ & - & - 0 & $\bullet \bullet$ & - & 0 & - \\
\hline 6 & $1 \mathrm{P}$ & 1 & - & - & - & - & - & - & - & - & - & - & - & - & - & - & - \\
\hline 6 & $1 \mathrm{P}$ & 2 & - & - & - & - & - & - & - & - & - & - & - & - & - & - & - \\
\hline 6 & $1 \mathrm{P}$ & 3 & - & - & - & - & - & - & - & - & - & - & - & - & - & - & - \\
\hline 6 & $1 \mathrm{P}$ & 4 & - & - & - & - & - & - & - & - & - & - & - & - & - & - & - \\
\hline 7 & $1 \mathrm{P}$ & - & $\mathrm{N}$ & $\mathrm{N}$ & $\mathrm{N}$ & $\mathrm{N}$ & $\mathrm{N}$ & $\mathrm{N}$ & $\mathrm{N}$ & $\mathrm{N}$ & $\mathrm{N}$ & - & $\bullet \bullet$ & $\bullet \bullet$ & - & $\bullet$ & - \\
\hline+ & $3 \mathrm{P}$ & SFO & $\mathrm{N}$ & $\mathrm{N}$ & $\mathrm{N}$ & $\mathrm{N}$ & $\mathrm{N}$ & - & - & - & $\bullet \bullet$ & - & $\bullet \bullet$ & $\bullet \bullet$ & - & $\bullet$ & - \\
\hline+ & $1 \mathrm{P}$ & Fresno & - & - & - & - & - & - & - & - & $\bullet \bullet$ & - & - & - & - & $\bullet$ & - \\
\hline
\end{tabular}

KEY:

Events: • indicates significant PQ event recorded, $\circ$ indicates non-significant (greater than $87 \%$ voltage remaining) event recorded, $\mathrm{N}$ indicates sensor not in service.

Sensor Type: 1P are single-phase sensors, 3P are three-phase sensors 


\subsubsection{July 1, 2002 Car-Pole Accident near Firm 1}

Firm 1 installed six I-Sense monitors at one manufacturing site. A facility expansion left the older and newer halves of the building with independent electrical systems. The plant electrical loads are approximately evenly divided between two utility transformers that connect to separate utility distribution "blocks." Three monitors were installed on each bus within the plant, as shown schematically in Figure 8. One three-phase sensor was located near the service entrance, a second three-phase sensor was located near load buses within the building, and a single-phase sensor was located at a branch circuit outlet within the building.

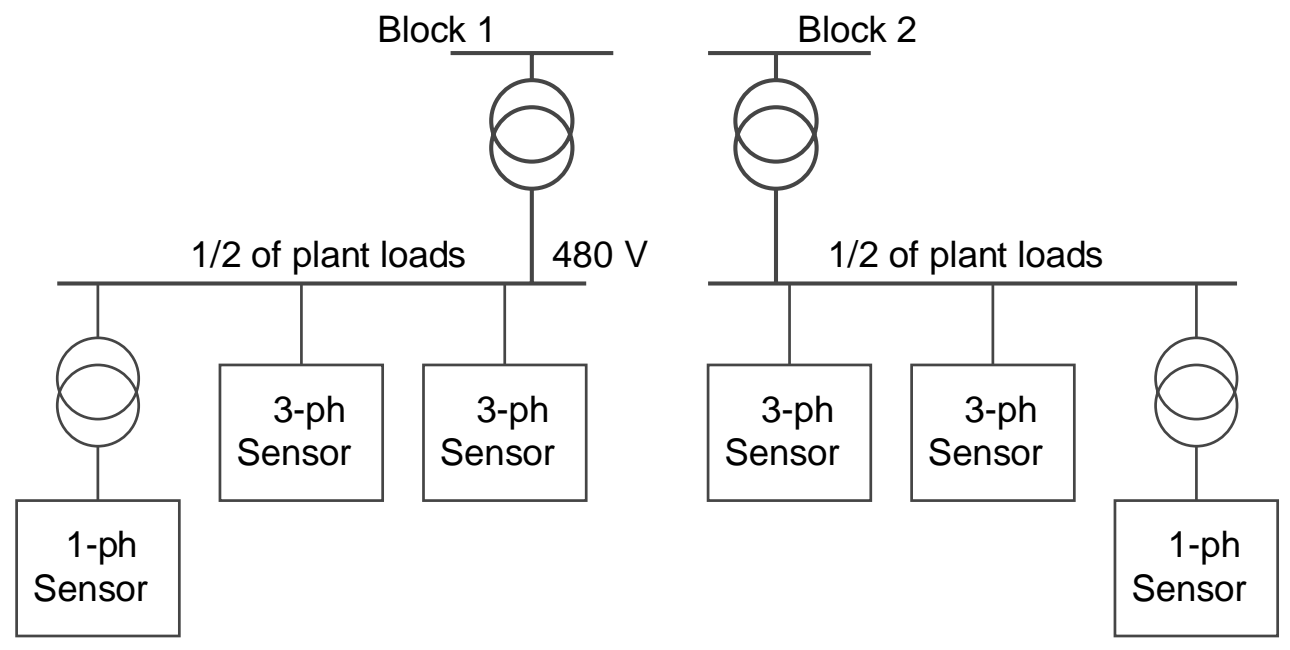

Figure 8. Sensor locations within Firm 1.

On July 1, 2002, the three monitors on bus "Block 2" reported a 9.6-minute interruption event (outage) at 10:54 a.m. Neither the three monitors on bus "Block 1" nor other I-Sense monitors in the Silicon Valley (SV) area reported electricity-reliability or power-quality events at this time.

In a subsequent interview, the facilities manager stated that a car had struck a utility pole near the site and that the utility line crew was forced to de-energize the line to extricate the car. Distribution bus "Block 1" was not affected.

This is a clear example of an externally caused event that affected only the local distribution system. Firm 1 did not provide an estimate of the costs of the process interruption caused by this event but has reported that the restart time for some manufacturing processes can take three days and that plant revenue is approximately $\$ 500,000$ per day at full operation.

\subsubsection{October 19, 2002 Short Voltage Sag Event at Firm 1}

On October 19, 2002, all six monitors at Firm 1 reported a short-duration voltage sag at 8:27 a.m. The captured event voltage waveforms from two monitors on buses Block 1 and Block 2 are shown in Figure 9. The nearly identical waveform signatures, together with the knowledge that the plant buses are not inter-tied, indicates that this event was externally caused and propagated on the distribution grid. No other I-Sense monitors in the SV area reported events at 
this time, which further suggests that the root cause occurred on the distribution or subtransmission grid, not on the transmission grid.

Firm 1 did not report a process interruption associated with this event.
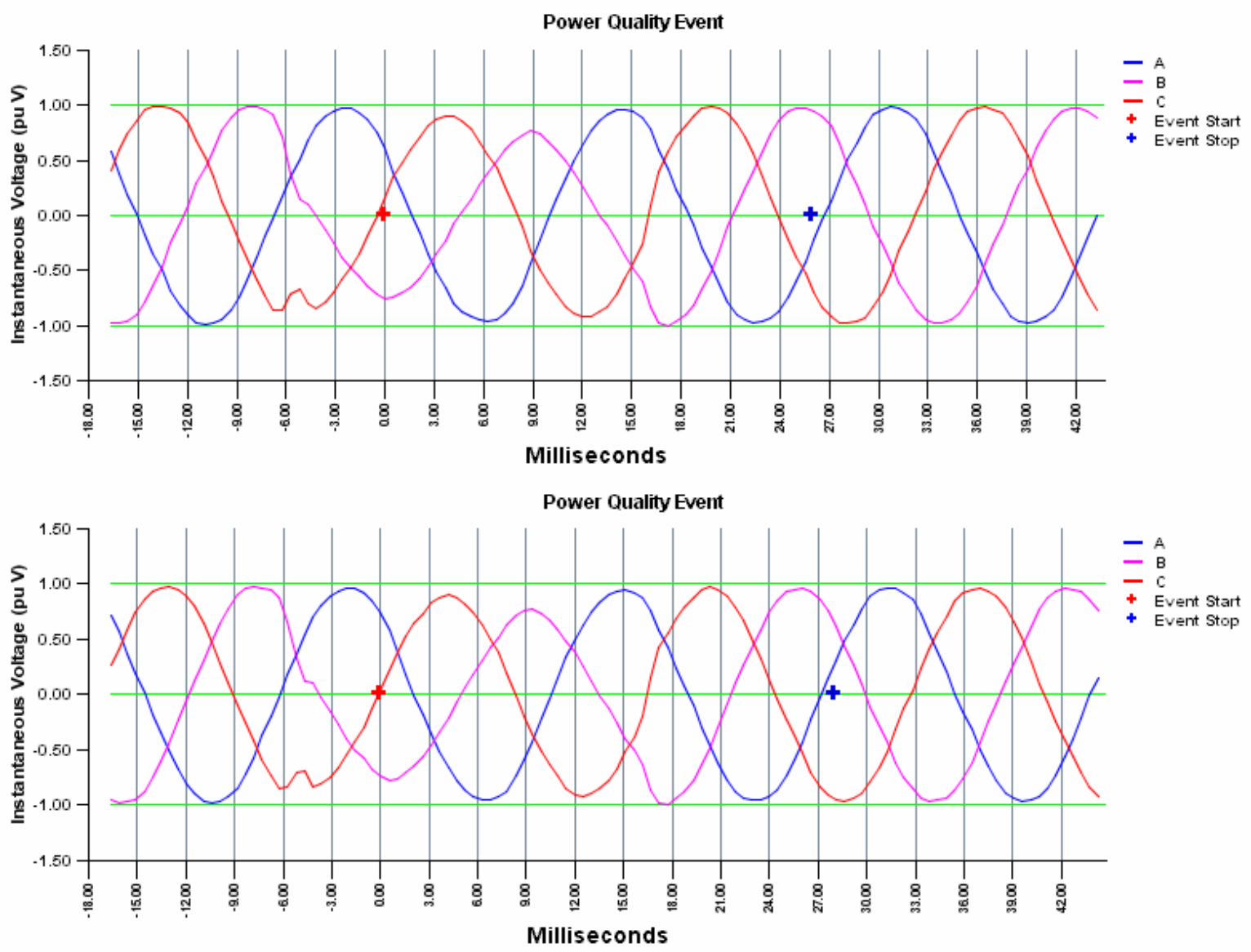

Figure 9. 10/19/02 event voltage waveforms: Block 1 event (top) Block 2 event (bottom). Both are 480V L-L sensors.

\subsubsection{November 7, 2002 Region-wide Wind Storms}

A major windstorm swept through California on November 7, 2002. Voltage sags were reported by monitors across the SV area. Figure 10 summarizes one widespread event recorded at 11:41:28 p.m. by 16 different monitors at twelve locations, including those at Firm 1. The voltage sag severity was greatest in the area of Firm 1. A simultaneous event was also recorded near Fresno, in the Central Valley. Captured rms voltage profiles from four sites are shown in Figure 11.

This event was felt across the SV region at all monitored locations except one. A likely conclusion is that a weather-related, transmission-level fault caused the voltage-sag event. PG\&E, in its 2002 reliability report to the California Public Utilities Commision, lists major reliability events on November 7-8, 2002, caused by storms with winds gusting up to $90 \mathrm{mph}$. 
A less-widespread pair of voltage sag events was recorded by seven sensors, including five of the six sensors at Firm 1, earlier in the day at 5:55:53 PM and 5:55:57 PM.

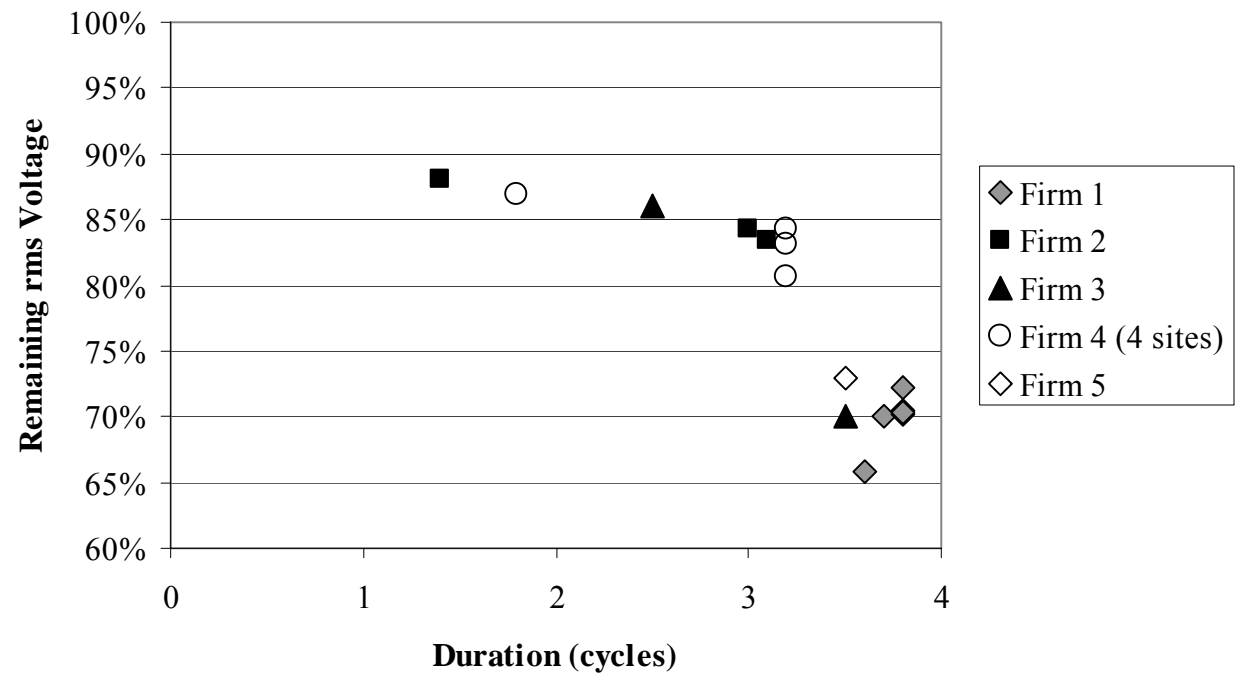




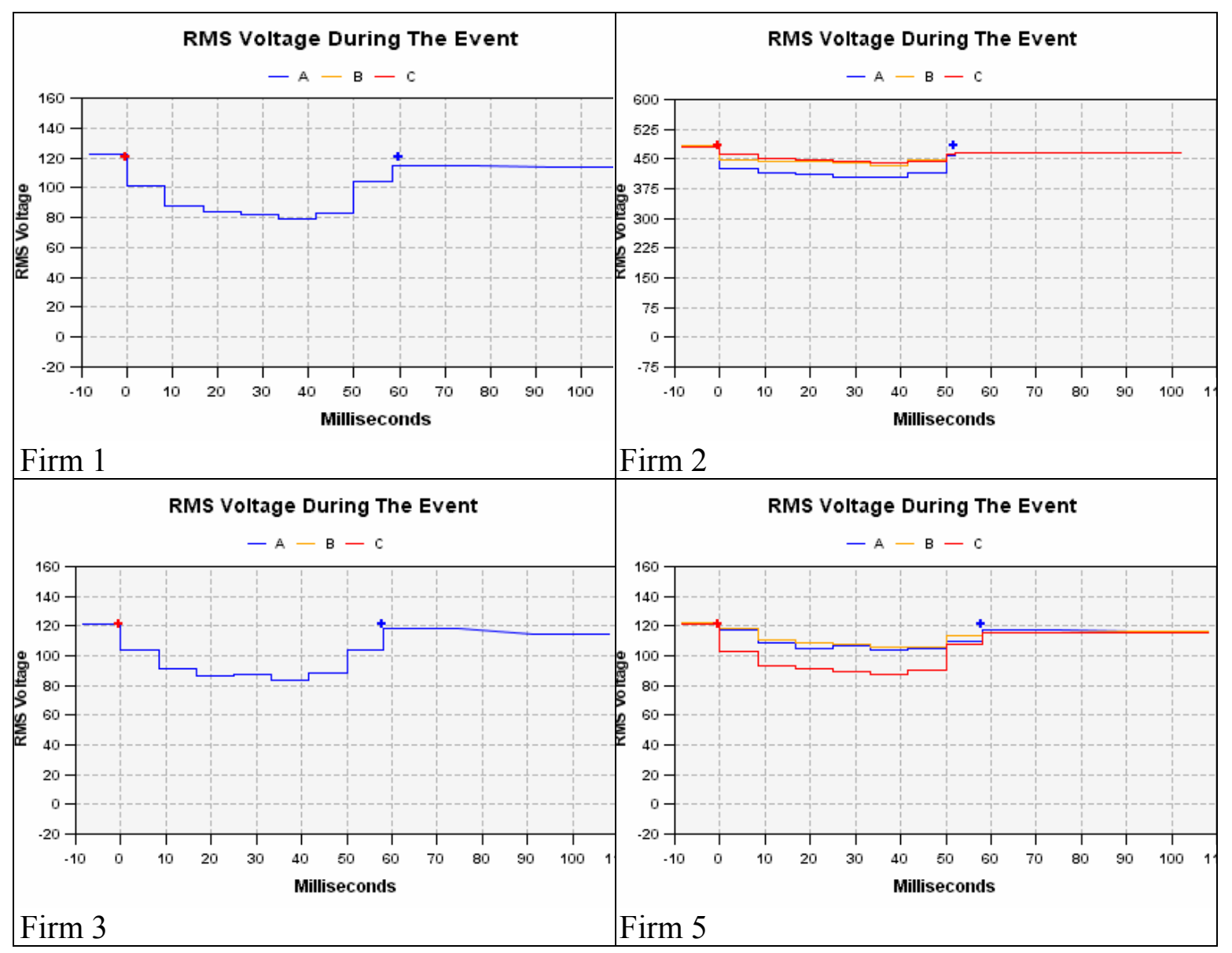

Figure 10. 11/7/02 typical event rms voltage profiles at four sites.

\subsubsection{December 27, 2002 Firm 3 Campus Distribution Transformer Failure}

Firm 3 installed single-phase I-Sense monitors in two separate buildings on a single campus. At 7:02 p.m. on December 27, 2002, one of the two monitors reported a one-minute interruption followed 22 minutes later by a 67-minute interruption. In a subsequent interview, the site facilities manager reported that a distribution transformer (owned by Firm 3 ) had failed on that evening. At least one campus building was without power for several days until a replacement transformer could be located.

Firm 3 is served directly at 115 kilovolts $(\mathrm{kV})$. No other monitors in the area recorded significant events during the same period. This case demonstrates an internally caused powerquality event that did not affect the regional power grid.

\subsubsection{January 23, 2003, Airplane Hit 500-kV Transmission Line}

A Cessna Cirrus SR20 crashed in the Evergreen Foothills northeast of San Jose on January 23, 2003. National Transportation Safety Board officials said the airplane dropped from radar at around 5 p.m. Pacific Gas and Electric Company (PG\&E), the utility serving the area, said the plane hit the $500-\mathrm{kV}$ transmission line that feeds the San Jose area. PG\&E reported that the 
plane damaged seven spans of wire and destroyed five or six cross arms but did not cause any power outages.

At 4:53 p.m., all four three-phase monitors at Firm 1 recorded a three-cycle-duration voltage sag to 80 - to 84-percent remaining rms voltage. One of two single-phase monitors at Firm 3 and a monitor at Firm 4 recorded similar voltage sags with the same timestamp. Less than one second later, both monitors at Firm 3 reported interruptions: one monitor saw a one-minute interruption, and the other saw a 42-minute interruption. No other monitors in this study recorded an interruption or further voltage sags. Six minutes after the time that the 42-minute interruption ended, the other Firm 3 monitor, which had earlier seen only a one-minute interruption, reported a two-cycle interruption.

Firm 3 has cogeneration that provides 80 to 85 percent of campus power requirements during onpeak hours. In this case, a relatively insignificant transmission-level, power-quality event may have been exacerbated at Firm 3 by local switching practices associated with the cogeneration.

\subsubsection{February 2, 2003 Transmission Level Event, Possibly Caused by Earthquake}

An earthquake followed by multiple aftershocks struck the SV region on February 2, 2003 at 10:23 a.m. and 10:47 a.m. The quake epicenter was five kilometers $(\mathrm{km})$ southeast of San Ramon, California. The United States Geological Survey classified shaking as "severe" throughout the area of this study. ${ }^{10}$ Later that day, two separate power-quality events, 15 seconds apart, were detected at 5:19 p.m. by 14 monitors in the SV study area as well as by other I-Sense monitors in South San Francisco and 70 km (45 miles) east of Livermore, near Fresno, in the California Central Valley.

Figures 12 and 13 show three-phase monitor data from two sites approximately $20 \mathrm{~km}$ (13 miles) apart in the western SV area. Apparently, a single-line voltage sag was propagated on the transmission network. Of the monitors that did not record these two events, all were singlephase monitors that may be connected to a phase voltage that was not affected by the events.

The actual cause of the transmission-level, power-quality events is not known to the authors of this report. However, the coincidence of the events with the earthquake and aftershocks suggests a possible correlation.

\footnotetext{
${ }^{10}$ Source: http://quake.usgs.gov
} 
Pilot Evaluation of Electricity-Reliability \& PQ Monitoring in CA's Silicon Valley with the I-Grid System
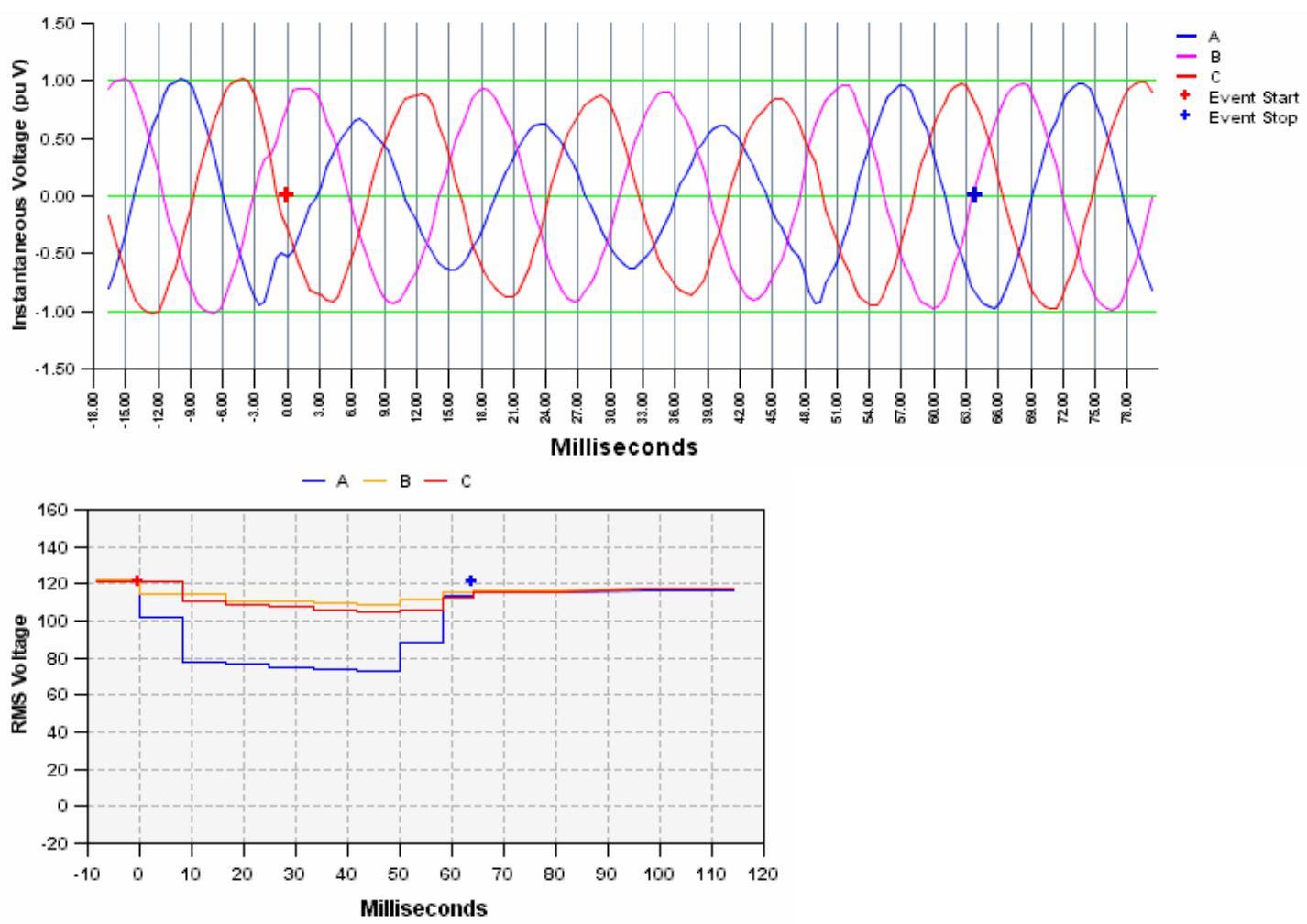

Figure 11. 2/2/03 event voltage waveform (top) and rms voltage profile (bottom), captured by 120 volt L-N monitor. 

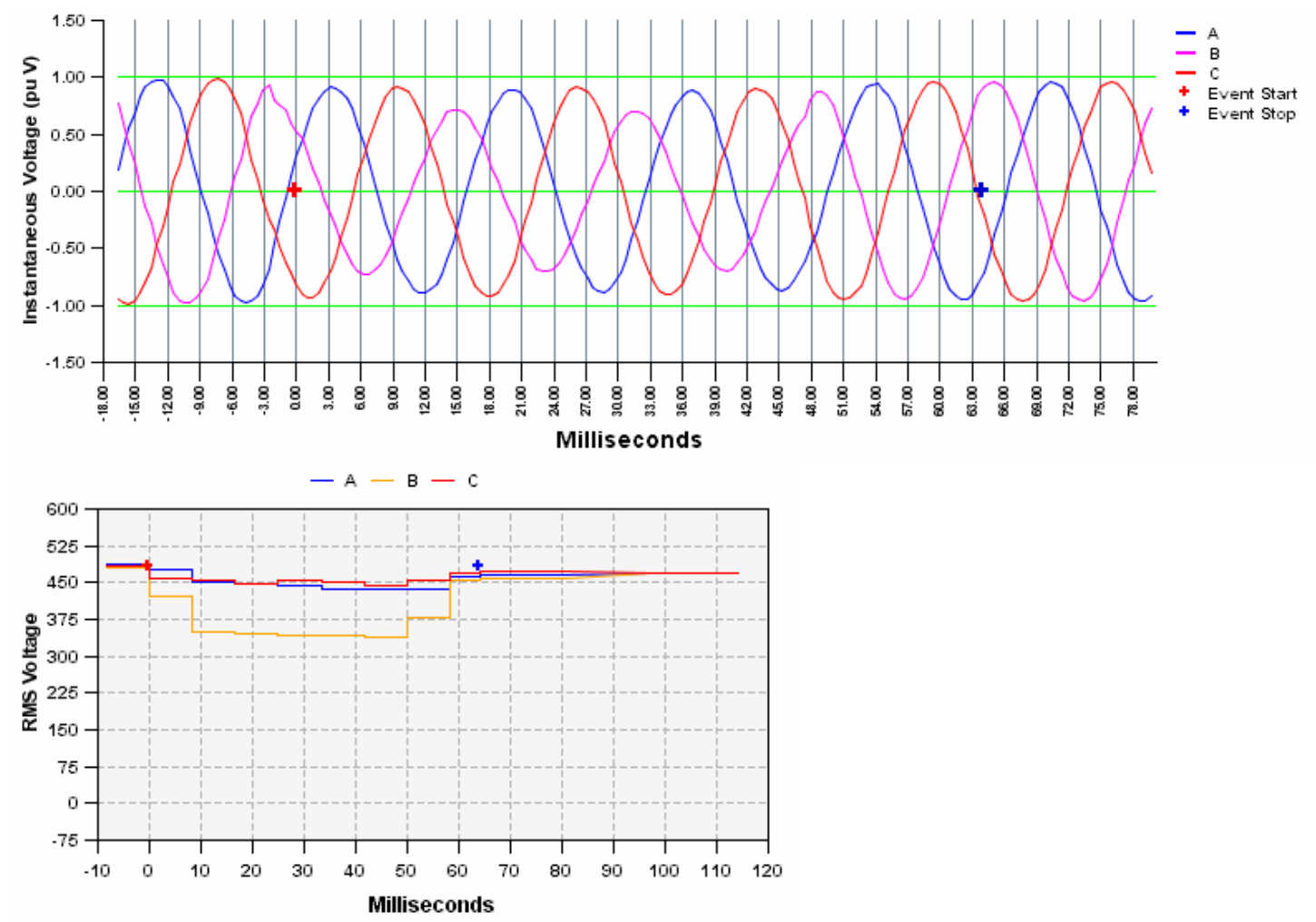

Figure 12. 2/2/03 event voltage waveform, (top) and rms voltage profile (bottom) captured by 480 volt L-L monitor.

\subsection{Summary of Findings from Pilot Data Collection}

The data collected in this pilot project support the following observations:

1. Power-quality and reliability events occur with some frequency.

2. There is preliminary evidence to suggest that, consistent with common wisdom, the frequency of power-quality events decreases as delivery voltage increases.

3. Judicious placement of I-Grid monitors allows classification of events according to whether the events originate within or external to a customer's premises.

4. Correlation of events among multiple monitors permits identification of grid- level events affecting other customers who do not have monitors. 



\section{Customer Views on Electricity Reliability and Power Quality}

Interviews conducted with each of the pilot study participants were an important complement to the information collected by the I-Grid monitoring system. The goal of the interviews was to understand the value the participants place on electricity reliability, particularly power quality, and to identify emerging trends and issues in the participants' efforts to address reliability and power-quality issues.

The interviewees were generally lead staff members from the facilities departments of each firm. One participating firm has outsourced its management of utility services, including treatment of reliability and power-quality issues, so we were granted permission to interview the third-party firm handling these services. Another participating firm provides power-quality consulting services; we interviewed the president of this firm. Another firm sells electrical supplies, including power-quality mitigation products; we interviewed the principal sales engineer for these products.

Participants granted interviews based on the understanding that their responses would be confidential. To respect this agreement and to assemble the information we gathered in a coherent presentation, we identified several thematic issues addressed in the interviews and organize our results around these topics:

- The economic cost of power-quality and electricity-reliability problems,

- Perceptions regarding electricity reliability and power quality, including utility relations,

- Steps taken to address power-quality and electricity-reliability issues, including paybacks on investments; and

- Barriers to implementing solutions to electricity-reliability and power-quality problems.

\subsection{The Economic Cost of Electricity-Reliability and Power-Quality Problems}

The participants in the pilot study generally place a very high premium on ensuring power quality and electricity reliability. Their participation in this pilot is a direct reflection of their business interest in this topic. Therefore, it was no surprise that they were readily able place a quantitative value on these aspects of electricity service. The quantitative values given by our study participants are shown in Table 2. We believe that this level of understanding is likely to be limited to sophisticated electricity users such as those who participated in our project.

The first key observation is that, from the customer's point of view, the costs associated with an electricity-reliability or power-quality event depend more on the manufacturing or process downtime that results from an event, not necessarily on the duration of the event. That is, when asked about the value or economic costs of electricity reliability and power quality, the interviewees generally responded with cost information linked to downtime, not the duration of the event. One participant observed that "Customers do not make distinctions about the causes of machine downtime; all they know is that their machinery has stopped functioning." We also believe this sentiment results, at least in part, from that participant having had relatively rare experiences with extended outages (events lasting more than a few minutes) and relatively frequent experiences with power-quality events and short-duration interruptions (events lasting a few minutes or less). 
Table 2. The Economic Costs of Electricity Reliability and Power Quality

\begin{tabular}{|l|l|l|}
\hline Business Type & Event Description & Economic Cost (\$) \\
\hline $\begin{array}{l}\text { Manufacturer of } \\
\text { silicon-chip } \\
\text { fabrication } \\
\text { equipment }\end{array}$ & $\begin{array}{l}\text { Voltage sags and short-duration voltage } \\
\text { interruptions }\end{array}$ & $\$ 350,000$ per event \\
\hline $\begin{array}{l}\text { Silicon-chip } \\
\text { fabrication }\end{array}$ & $\begin{array}{l}\text { Even an outage of a few minutes can lead } \\
\text { to } 1-1.5 \text { days of downtime }\end{array}$ & $\begin{array}{l}\text { Up to } \$ 500,000 \text { per } \\
\text { day in lost revenue }\end{array}$ \\
\hline $\begin{array}{l}\text { Automotive } \\
\text { manufacturing }\end{array}$ & $\begin{array}{l}\text { From a few seconds to one half-hour of } \\
\text { downtime }\end{array}$ & $\begin{array}{l}\text { Less than } \\
\$ 1,000,000\end{array}$ \\
\cline { 2 - 3 } & More than 1 hour of downtime & In the millions \\
\hline $\begin{array}{l}\text { Financial } \\
\text { clearinghouse }\end{array}$ & $\begin{array}{l}30 \text { minutes of downtime because of a } \\
\text { lightning strike }\end{array}$ & $\$ 12,000,000$ \\
\hline
\end{tabular}

Several participants offered supporting information to help place the monetary values in perspective. For example, one offered valuable insight on the often-cited statistic that an outage costs silicon-chip fabricators $\$ 1$ million per event. He said that this value depends largely on whether the chips have already been sold and the plant is currently operating at full capacity. The determining factor is whether the downtime results in the firm missing a deadline for delivery of chips that have already been sold. He pointed out that, in 2003, many firms were running at less than full capacity. Under these conditions, lost production from an outage could be made up through overtime (which is not possible when a plant is running at full capacity) and that the costs of materials lost as a result of the outage were minimal in comparison to the financial penalties that would be associated with missing shipping delivery dates. The chip fabricator participating in our study reported that outages of even a few minutes could sometimes lead to 1 to 1.5 days of downtime, causing the firm to forego $\$ 500,000$ per day in revenues.

Traditionally, business-cycle issues such as those noted by this participant are not wellaccounted for in studies of reliability costs. A related example was provided by the manufacturer of silicon-chip fabrication equipment. As a final step before delivery of a new piece of fabrication equipment to a customer, the manufacturer must conduct a continuous, 1,000-hour factory test, which takes about six weeks. Any interruption during this period requires restarting the entire test from the beginning. Consequently, the cost of an interruption during this period is much greater for this firm than the cost when a new piece of equipment is not undergoing factory testing. This firm reported that it had recently made a $\$ 2.5$-million investment in equipment to improve electricity reliability that paid for itself in nine months, which translates into an implied cost per outage of $\$ 350,000$ per event. (We discuss the high returns on electricity-reliability and power-quality technology investments in the subsection below on steps taken to address reliability and power-quality issues.)

The monetary penalties for missing deliveries are especially high in the financial services industry. For these firms, "missed" deliveries refer to financial transactions that cannot be executed. Financial clearinghouses, for example, provide written guarantees for maximum allowable downtimes in the contracts they sign with their customers (e.g., banks that offer credit cards). Stringent financial penalties, based in part on the value of foregone or inaccurate 
transactions, result from exceeding pre-specified limits. As a measure of the great value placed on reliability by this type of firm, we were told that: "These customers never ask how much it's going to cost to fix the problem; they only want to know how quickly the solution can be implemented." We were told of a financial clearinghouse in Texas that had experienced a \$12million loss as the result of a 30-minute outage caused by a lightning strike.

We also heard that the costs of downtime have been growing over time for participants. One participant reported that "Problems that used to cost \$2-300,000 per event now cost in the millions per event." We explore some of the reasons for this increase in vulnerability to reliability and power-quality problems in the next subsection.

\subsection{Perceptions of Power Quality and Electricity Reliability, Including Utility Relations}

Customer awareness of electricity-reliability and power-quality problems and understanding of the root causes of these problems are critical factors in evaluating the actions that customers have and have not taken to address these problems.

Among the individuals we interviewed, awareness of electricity-reliability and power-quality issues is fairly high. Many had received professional training on the subject.

However, it is important to recognize that awareness of power-quality issues, in particular, is not widespread. To be aware of the problem, a customer must have equipment that is sensitive to power-quality problems, and this sensitivity must have a material effect on operations. One participant indicated that he was not specifically aware of power quality as an issue in operations at his firm mainly because the firm does not have much susceptible equipment and more importantly, because he has not received complaints that could be traced to power-quality problems.

Power-quality problems manifest, as noted earlier, in faulty operation of equipment. However, power-quality problems are only one possible cause of equipment malfunction and are also difficult to observe, so it is not a simple matter for a customer to definitively determine that a power-quality event has caused an equipment problem. One participant in our study said that his primary clue that a power-quality event was to blame for equipment problems was the simultaneous failure of multiple pieces of equipment. His participation in the pilot study was motivated by the desire to confirm when power-quality issues are the sources of manufacturing problems. He noted that regular maintenance of equipment (to avoid downtime) was currently a bigger issue for his firm than power quality (in part because power-quality solutions had already been incorporated in the most critical of his company's processes). Another participant indicated that a key measure of the success of his firm's training programs is whether students can correctly identify power-quality problems (versus software problems) as the cause of an equipment fault.

Interestingly, the emergence of industry standards, such as SEMI F47 (for semiconductor manufacturers) and ITI/CBEMA (for office PCs), may have indirectly contributed to reducing awareness of the possibility that power-quality problems may affect operations. That is, some argue that specifying equipment that is in compliance with these standards means that powerquality problems have been adequately addressed. In fact, both standards only articulate 
thresholds above which equipment is expected ride through power disturbances; disturbances below these thresholds will still cause faulty operation or failure of equipment.

Understanding of the root causes of electricity-reliability and power-quality problems was mixed among our study participants. Some view "power quality" as an "internal" problem on the customer side of the meter and "reliability" as an "external" problem on the utility side of the meter. Yet in reality, power-quality problems may emerge from actions arising on either side of the meter.

More than one participant perceived the majority of power-quality problems to result from improper or poor grounding practices, which is an internal problem; one participant stated that up to 95 percent of all power-quality problems could be attributed to grounding problems within a customer's premises. Participants suggested that proper grounding practices, as prescribed by the National Electric Code in part to prevent power-quality problems, are often not implemented. Renovation and expansion of existing facilities were noted as frequently leading to grounding problems and thus to power-quality problems.

Other participants were aware that power-quality problems could emerge from actions and events on the utility side of the meter. Many had implemented power-quality solutions based on careful assessments of the frequency of power-quality events coming from the utility side of the meter. At least one large customer had worked successfully with his utility to change the schedule for a routine utility operation that regularly disrupted his plant's operations.

Participants' experiences with utility power-quality and reliability issues varied widely. We have already cited the experience of one participant who was not specifically aware of powerquality events significantly affecting his operations. Others had detailed recollections. Among industrial electricity consumers, we found the number of power-quality-related experiences were, by and large, correlated with the voltage at which each customer took service from the utility. On the low end, the one participant with service at transmission voltage recalled four to five voltage sags during the past five years or about one sag per year on average. On the high end, one participant with service at distribution voltage based his decision to invest in a power-quality solution on a desire to avoid an average of nine events per year based on data taken during three years.

Perceptions of utility responsiveness to power-quality problems were neutral to slightly positive. More than one participant noted that the utilities had made efforts to be responsive to powerquality concerns. As noted earlier, more than one participant cited their utility's willingness to modify its operations to eliminate recurring voltage sags that took place during a critical time for the customer's operations. It is important to bear in mind that several of the participants are very large electricity consumers, so it is not surprising that utility service representatives are very responsive to these customers.

Apparently, utilities in the recent past offered power-quality consulting services to customers. However, these efforts have been dropped as a result of changing corporate priorities at utilities and customers' preferences for third-party assistance in identifying and addressing power-quality problems. 


\subsection{Steps Taken to Address Electricity Reliability and Power Quality, Including Payback on Investments}

Each of the participants in our study has taken action to address reliability and power-quality issues. These actions have mostly been highly cost effective - often more cost-effective than standard investment criteria (e.g., less than a two-year payback). Hardware solutions have tended to dominate. We will explore some of reasons for this bias in the final subsection on barriers, below.

Perhaps the most common theme of the strategies undertaken by participants to address electricity-reliability and power-quality issues was reliance on a "bottom-up" approach. Insulating or hardening individual equipment or, in some cases, the controls for equipment was the most common approach selected by participants. Typically, a dedicated uninterrupted power supply (UPS) was installed. In one case, constant-voltage transformers were installed to protect the controls for each piece of equipment in a manufacturing process.

Increasingly, equipment manufacturers are addressing reliability and power-quality issues in response to customer demands. Specifying equipment that is in compliance with SEMI F47 or CBEMA is now a common practice. Many manufacturers offer power conditioning systems embedded in their machines as the means of ensuring compliance.

Where susceptible processes were or could be co-located, we found more systematic solutions. These solutions typically involved UPS integrated with back-up generation serving multiple machines or processes. Data-processing facilities were commonly centralized and hardened in this manner.

Recognition that most power-quality events were the result of routine operations on the utility's distribution system has led some customers take utility service at a higher voltage. This strategy has been expensive but highly effective for some participants in our study.

We asked participants about recent heightened concerns in California over rolling blackouts and the trend toward outsourcing of operations. We speculated that moving operations out of the SV area might be perceived as an effective strategy for addressing reliability and power-quality concerns. By and large, the typical response was that the economic forces driving firms to move manufacturing (including power-quality-susceptible processes) out of the SV area were related to larger-scale concerns than power quality. One participant observed that moving manufacturing to Southeast Asia simply amounted to trading vulnerability to Silicon Valley power-quality problems for vulnerability to the power-quality problems of Southeast Asian utilities. Only one participant cited reliability and power quality as a consideration in a corporate decision to move data processing to a central facility in another part of the U.S. where the firm's new facility had been specifically designed to insure higher levels of resilience to reliability and power-quality problems (among other features that were incorporated into its design).

Most of the actions taken by the firms we interviewed to reduce vulnerability to electricityreliability and power-quality problems have been highly cost effective. Payback periods that were disclosed for specific investments were generally shorter than two years. It was noted that 
in the electronics industry, investments with payback periods longer than two years longer are simply not considered. One participant said his firm's payback criterion was 18 months.

With respect to paybacks, it appears that there is much low-hanging fruit. One participant cited a recent \$2.5-million investment that paid for itself in nine months. Another investment paid for itself in six months by preventing a single shutdown; shutdowns had previously been occurring once or twice a year.

Back-up generation was a subject that drew mixed reactions. Fears of rolling blackouts had led many firms to make substantial investments in back-up generation during 2001 and 2002. However, few firms actually experienced rolling blackouts. Some firms are served by municipal utilities that were not affected by the rolling blackouts of 2000 and early 2001. Several firms joined PG\&E's Optional Binding Mandatory Curtailment program, which allowed them to avoid subsequent rolling blackouts in return for immediately dropping load in response to a call from the utility. ${ }^{11}$ But, most important of all, there were no calls for rolling blackouts during the summer of 2001 or 2002. At least one participant indicated that there was some bitterness among firms that had invested in back-up generation to protect against rolling blackouts that did not materialize.

\subsection{Barriers to Iimplementing Electricity-Reliability and Power-Quality Solutions}

In an earlier subsection, we touched broadly on the lack of awareness and understanding as barriers to implementation of electricity-reliability and power-quality solutions. In this final subsection, we address barriers specifically by focusing on the roles of education/training, company organizational structure, and corporate practices and decision making.

\section{Education/Training}

Participants involved in the pilot project had all received modest to significant professional training in electricity-reliability and power-quality issues. One had authored a standard industry textbook on power-quality monitoring. These participants, in our opinion, are not representative of the majority of staff in firms addressing electricity-reliability and power-quality issues in the industry today.

Several participants mentioned education and training as the key to improving businesses' ability to address electricity-reliability and power-quality issues in an economically efficient manner. One participant proposed that the current bias toward hardware solutions was a direct result of the poor understanding among many facilities staff members of the root causes of most powerquality problems (namely, grounding problems within facilities).

One participant opined that, "Generally, approaches to addressing reliability problems are reactionary and made hastily; they are often not well thought-out. The result is to try to fix what

\footnotetext{
${ }^{11}$ An interesting anecdote we heard was that many firms found that they could easily shed 30 percent of load with little or no impact on operations. Some recognized these as energy-efficiency opportunities (i.e., as evidence that this load could be reduced all the time, not just in response to system emergencies); nonetheless, these opportunities to save energy were not usually implemented. It was never suggested that these low-cost opportunities to save energy were passed up to maintain a higher baseline.
} 
appears to be hurting without determining the real underlying problems. This lack of understanding often leads to overspending on expensive hardware solutions when a much less expensive solution would be equally (or more) effective. For example, rotating machinery can ride through a momentary loss of power, so protecting the controls alone, rather than sizing a UPS to carry the load of the entire machine, would be a much cheaper solution."

\section{Organizational Structure}

As we learned more about how firms addressed electricity-reliability and power-quality problems, we gained a greater understanding of how firms' organizational styles affected their ability to address these problems. Most participants in the pilot study were staff from the facilities engineering departments of their firms and were generally responsible for all utility services, including electricity, gas, and water. Facilities staff typically become involved in addressing electricity-reliability and power-quality problems when these problems are raised by production staff ("something is not working; please fix it now.")

As noted previously, we were led to believe that facilities staff generally do not have extensive training in electricity-reliability and power-quality issues. At one participating firm, we interviewed a third party that had been hired specifically to provide specialized expertise in addressing electricity-reliability and power-quality issues. In this instance, expertise was brought in house by outsourcing this aspect of the firm's facilities maintenance and operations.

In some firms with highly specialized equipment, facilities staff share responsibility with production engineering staff for identifying and addressing electricity-reliability and powerquality problems. Production engineering staff typically propose solutions for individual equipment; facilities staff may be able to take a more systematic view of solutions to the problems. In these collaborative settings, ensuring good communication and coordination between these two staffs is critical to addressing problems effectively.

One participant suggested that neither facilities nor production staff was the appropriate organizational entity to address electricity-reliability and power-quality issues. In his opinion, quality-control staff were the appropriate entity to recommend solutions to these problems because these staff members are in the best position to assess solutions from the standpoint of the net impact on a firm's productivity.

\section{Corporate Practices and Decision Making}

A final set of barriers to addressing electricity-reliability and power-quality issues is corporate practices and decision making. To some extent, we believe this barrier to be the most fundamental and challenging. That is, addressing both of the types of barriers discussed above, education and training and organizational structure, depends ultimately on corporate recognition of and motivation to address electricity-reliability and power-quality problems.

One participant observed that a major challenge for firms addressing power-quality and electricity-reliability problems is that traditional accounting systems make it difficult to quantify the full dollar impact of these problems. If these cost impacts are not reliably accounted for, economic justification of actions or investments to address them is very difficult. 
Even with reliable accounting, capturing the attention of senior management is an ongoing challenge. More than one participant noted that the attention of senior management is a scare commodity. Problems must rise to a significant level to gain attention. Although focused attention may be devoted to solving a problem that is perceived as significant, attention is often easily diverted, if a solution is not found quickly, to other newer problems that appear more pressing. In this regard, heightened public awareness of electricity issues in California has likely had a positive effect on firms' effectiveness in addressing electricity-reliability and powerquality issues. According to one participant: "Deregulation moved electricity, as an issue, to the board room."

Related to this observation, another participant offered "Power quality has always been a tough sell from the beginning. No one wants to buy insurance. The motivators are the usual ones: fear, uncertainty, and doubt." He went on to relate "Executive interest is directly related to the time since the most recent bad experience: today, no one is buying gen-sets. I call this the "half-life" of pain."

Even with awareness and attention to electricity-reliability and power-quality problems, idiosyncrasies of corporate decision making sometimes take precedence. One participant recounted an anecdote in which a power-quality solution with a 7.5-hour payback was passed up because, if installed, it would take up space that would require reducing the number of machines that could operate in the facility. With the power-quality solution, the throughput of the remaining fleet of machines would have more than compensated for the lost output of the machine that would have more than compensated for the lost output of the machine that would have been displaced. 


\section{Toward Development of a Living National Database of Electricity Reliability and Power Quality}

One aim of this pilot project was to evaluate the I-Grid system as a vehicle for improving the quantity and quality of information about power quality that is available in the public domain. The I-Grid system has two key features that could facilitate creation of a living, national database of power-quality information. First, the low cost of the I-Grid monitors makes possible much wider deployment than would be possible with reliance on traditional, more expensive monitors. Second, uploading of the information from individual monitors to a central database enables easy access, aggregation, and analysis of information from a large number of monitors. Synchronization of all sensors to the central database server, and of the server to the NIST standard clock, allows aggregation across wide areas.

This section reviews experiences from the pilot project that highlight considerations and issues relevant to wider deployment of the I-Grid. The information has been grouped under the following subtopics: recruiting participants and installing monitors; improving central database infrastructure; and improving data aggregation and analysis.

\subsection{Recruiting Participants and Installing Monitors}

Recruitment of participants for the pilot project was a time-consuming process. Weeks and sometimes months passed between firms' initial agreements to participate, and the final installation of monitors. Although recruitment was straightforward, installation was hampered by key site-specific considerations.

\section{$\underline{\text { Recruitment }}$}

Generally speaking, reaching agreement to participate was very straightforward. There was strong interest in the project. Participants were motivated both by the desire to acquire powerquality information at low cost and by a sense of good corporate citizenship to support a DOE study. Guarantees of the confidentiality of firms' proprietary information, though important, did not appear to be major consideration in the decision to participate, with one exception. We assume that future deployment of I-Grid monitors will be driven by the business interests of either customers or utilities. Customers will have a need for power-quality monitoring; utilities will be seeking to improve customer service by providing enhanced power-quality monitoring. Thus, recruitment is not likely to be a significant issue.

Installation

Installation of monitoring sensors was not such a simple matter, however. The process was hampered by two, key, site-specific considerations. First, the monitors require phone lines for uploading information to the central database and downloading software upgrades. Access to phone lines was complicated by: 1) the need to schedule phone-line installation (often involving another department or requiring a contractor); 2) difficulties in installing phone lines at locations where it was most desirable to monitor power quality (e.g., at specific machines/processes on a factory floor); and 3) initial opposition from IT Department personnel in some companies to sending data our of their buildings. Second, for the three-phase monitor, it is necessary to coordinate installation with scheduled downtime and to employ the services of a trained electrician. 
SoftSwitching Technologies is developing an I-Grid monitor that is based on wireless communications technology. This development should facilitate installation of future monitors. However, it also increases the cost of the monitors.

\subsection{Central Database Infrastructure}

Currently, the I-Grid sensors upload information to a central database. The database exhibited no problems handling the information provided by the 22 I-Grid monitors in this study as well as information from roughly 800 additional I-Grid monitors that were installed independent of this study. However, a nationwide array of perhaps 50,000 monitors would require reassessment and likely enhancement of the existing database infrastructure to increase data acquisition, storage, and analysis capabilities.

In addition, system modifications should be undertaken to accommodate information from a wide variety of power-quality monitors. The richness of the database and the rate at which it can be populated will be greatly enhanced if power-quality monitors produced by other manufacturers can contribute information. Open data-transmission protocols should be developed to facilitate achievement of this goal.

\subsection{Aggregation and Analysis of Data}

This pilot project demonstrates that electricity-reliability and power-quality data can be collected from remote sites and aggregated and analyzed, permitting conclusions to be drawn about specific individual participants as well as about the state of the larger grid from which the participants receive power. For this project, many of these analysis activities were performed manually. Increasing the scale and scope of data collection requires the automation and standardization of aggregation, analysis, and reporting of information from the databaseincluding the careful normalization of data put into the public domain. These efforts should be prioritized by the specific objectives of those who will use the information.

Several types of analysis are of particular interest, including:

1. Increasing understanding of the extent of what can be learned from a network of monitors with and without knowledge of grid topology. We postulated that events recorded simultaneously on many monitors originated on the transmission system. We were also able to identify events that were localized to smaller geographic areas. It would be useful to assess the directionality of initiating events by examining timestamps more closely. A more densely concentrated network of monitors could also provide more precise localization of initiating phenomena.

2. Developing standard statistical reports, based on emerging industry standards for recording and reporting power-quality events, for use in benchmarking electricity reliability and power quality.

3. Integrating global information system (GIS) capabilities into the database, which would greatly improve our ability to determine the extent of outages or power-quality events. 
Pilot Evaluation of Electricity-Reliability \& PQ Monitoring in CA's Silicon Valley with the I-Grid System 



\section{Appendix. I-Sense Monitor Summary Specifications}

Table A1 contains summary specifications for the I-Sense web-enabled monitors. All user controls and data viewing are available through the I-Grid website; website summary specifications are included in Table A2. The only requirement for client software is a W3C HTML 4.01 compliant web browser.

\section{Table A- 1. Summary I-Sense Monitor Specifications}

Voltage Ratings
Input Range
Accuracy
Sample Rate
Event Detection
Event Time stamp
Event rms voltage recording
Event waveform recording
Data Logging
Temperature
Certifications
Software
User Interface
Communications

- $120 \mathrm{~V}, 1$-phase, $50 / 60 \mathrm{~Hz}$

- $120 \mathrm{~V}(\mathrm{~L}-\mathrm{N}) / 208 \mathrm{~V}(\mathrm{~L}-\mathrm{L}), 3-$ phase, $50 / 60 \mathrm{~Hz}$

- $480 \mathrm{~V}(\mathrm{~L}-\mathrm{L}), 3$-phase, $50 / 60 \mathrm{~Hz}$

0 to $120 \%$ of peak nominal voltage. Input saturation (clipping) is flagged

Typically $\pm 0.2 \%$ of full scale, Max. $\pm 1 \%$ of full scale

True rms voltage computation

32 samples/cycle reported (with 3-times over sampling)

(1) half-cycle RMS voltage deviation: $<87 \%$ or $>115 \%$ of nominal

(2) Adaptive wave shape deviation algorithm

Based on SNTP Time Protocol, Synchronized to UTC, NIST reference via the I-Grid servers. Individual Sense monitors are typically synchronized to $\pm 0.1 \mathrm{~s}$

- rms voltage captured every half-cycle $(8.3 \mathrm{~ms})$ on each channel.

- For sustained interruptions, first 2 minutes of rms voltage data are captured.

32 points per cycle, up to 3 phases; maximum of 8 cycles captured: from -1 to +3

cycles at start of event, and -3 to +1 cycles at end of event end

Non-volatile event memory

Up to 200 events (1-phase units)

Up to 70 events (3-phase units)

Event time stamp, synchronized to UTC

10-minute $\mathrm{min} / \mathrm{max} / \mathrm{avg}$. rms data

Event Transmission criteria is user programmable

Verified event transmission to I-Grid servers clears internal data store

V.32bis (14.4kbps)/V.42 internal modem

Shared analog telephone line compatible

HTTP, TCP/IP, PPP, XML protocols for Internet communication to I-Grid servers

Local Internet POP provided for most locations

LED/button shows status,

other options configurable from I-Grid website

Rechargeable, long-life, 9V size

Enables dial out on sustained power interruption

$0^{\circ} \mathrm{C}$ to $45^{\circ} \mathrm{C}$

UL, CSA, FCC, CE, ICES

Field upgradeable via modem communication with I-Grid servers 
Pilot Evaluation of Electricity-Reliability \& PQ Monitoring in CA's Silicon Valley with the I-Grid System

\section{Table A- 2. Summary I-Grid Website Specifications}

$\begin{array}{ll}\text { User Interface } & \text { http://i-grid.com or https://I-grid.com (secure) website } \\ \text { Event Display } & \text { - Time stamp } \\ & \text { - rms voltage profile and voltage waveforms, for each channel (phase) } \\ & \text { - Magnitude vs. Duration plots of user selected events } \\ & \text { - Display events against ITI and SEMI F47 equipment susceptibility curves } \\ \text { Events classified } & \text { According to IEEE 1159: sags, swells, under-voltages, over-voltages, interruptions } \\ \text { Time Stamp } & \text { Based on SNTP Time Protocol, Synchronized to UTC, NIST reference } \\ \text { Event Storage (on-line) } & \text { Database capacity: greater than 10,000 events per monitor } \\ \text { Response } & \text { Data posted typically 90-120 s after event } \\ \text { Event Notification } & \text { Via email, with user-configurable notification criteria. }\end{array}$




\section{References}

Divan, D., G. Luckjiff, J. Freeborg, W. Brumsickle, D. Bielinski, and T. Grant. 2002. I-Grid ${ }^{\mathrm{TM}}$ : A New Paradigm in Distribution Grid Power Quality And Reliability Monitoring Proceedings, EPRI PQA North America Conference, June, 2002. Portland, OR.

Divan, D., W. Brumsickle, and J. Eto. 2003. A New Approach to Power Quality and Electricity Reliability Monitoring - Case Study Illustrations of the Capabilities of the I-Grid ${ }^{\mathrm{TM}}$ System. LBNL-52048. Berkeley, CA: Lawrence Berkeley National Laboratory.

Electrotek, Inc. 1996. An Assessment of Distribution System Power Quality; Volumes 1-3. EPRI TR-106294-V1-3. Palo Alto, CA.

EPRI (Electric Power Research Institute). 2003. Power Quality and Energy Measurement System Independent Evaluation Center: Test Results of Five Power Quality Monitors. Palo Alto CA: EPRI. 1001651. Eto et al. 2001.

Eto, J., J. Koomey, B. Lehman, N. Martin, E. Mills, C. Webber, and E. Worrell. 2001. Scoping Study on Trends in the Economic Value of Electricity Reliability to the U.S. Economy. Berkeley CA: Lawrence Berkeley National Laboratory. LBNL-47911. June.

ITI (Information Technology Industry Council). 2000. ITI (CBEMA) Curve Application Note, 2000. http://www.itic.org/technical/iticurv.pdf

Sabin, D., T. Grebe, and A. Sundaram. 1999. "RMS Voltage Variation Statistical Analysis for a Survey of Distribution System Power Quality Performance," Proceedings of the IEEE Power Engineering Society 1999 Winter Meeting, pp 1235-1240.

Sematech. 1999. Guide for the Design of Semiconductor Equipment to Meet Voltage Sag Immunity Standards. http://www.sematech.org/public/docubase/document/3760btr.pdf

SEMI. 2000. Standard SEMI F47-0200, Specification for Semiconductor Processing Equipment Voltage Sag Immunity.

Warren, C., D. Pearson, and M. Sheehan. 2003. "A Nationwide Survey of Recorded Information Used for Calculating Distribution Reliability Indices.” IEEE Trans. on Power Delivery, vol. 18, no 2, Apr 2003. 0885-8977/03. 